Trade Liberalization and Labor Market Dynamics

by

Rafael Dix-Carneiro, Princeton University

CEPS Working Paper No. 212

November 2010 


\title{
Trade Liberalization and Labor Market Dynamics
}

\author{
Rafael Dix-Carneiro* \\ Princeton University
}

November 12, 2010

\begin{abstract}
This paper studies trade-induced transitional dynamics by estimating a structural dynamic equilibrium model of the labor market. The model features a multi-sector economy with overlapping generations, heterogeneous workers, endogenous accumulation of sector-specific experience and costly switching of sectors. The estimation employs a large panel of workers constructed from Brazilian matched employer-employee data. The model's estimates yield high average costs of mobility that are very dispersed across the population. In addition, sector-specific experience is imperfectly transferable across sectors, leading to additional barriers to mobility. Using the estimated model as a laboratory for counterfactual experiments, this paper finds that: (1) there is a large labor market response following trade liberalization but the transition may take several years; (2) potential aggregate welfare gains are significantly mitigated due to the slow adjustment; (3) trade-induced welfare effects are very heterogeneous across the population; (4) retraining workers initially employed in the adversely affected sector may reduce losses incurred by these workers and increase aggregate welfare; (5) a moving subsidy that covers costs of mobility is more promising for compensating losers, although at the expense of higher welfare adjustment costs. The experiments also highlight the sensitivity of the transitional dynamics with respect to assumptions regarding the mobility of physical capital.
\end{abstract}

Keywords: Trade Liberalization, Labor Market Dynamics, Adjustment Costs, Worker Heterogeneity, Structural Econometric Models

*Email: rdc@princeton.edu. I am extremely grateful to my advisors Penny Goldberg and Bo Honoré for their incredible support and encouragement throughout this project. I am indebted to Donghoon Lee for valuable advice. I would also like to thank Nelson Camanho, Jan De Loecker, Gene Grossman, Rasmus Jørgensen, Marc Muendler, Andriy Norets, John Papp, Andrea Raffo, Steve Redding, Esteban Rossi-Hansberg, Andrew Shephard, Wilbert van der Klaaw and Kenneth Wolpin for feedback and suggestions. Many thanks to João De Negri and IPEA for granting me access to RAIS, and Princeton's Center for Economic Policy Studies for financial support. Part of this research was conducted at the Federal Reserve Bank of New York and at the Federal Reserve Board, whom I thank for the hospitality. Finally, I would like to gratefully acknowledge that the work reported in this paper was performed at the TIGRESS high performance computer center at Princeton and at the computer clusters of the Industrial Relations Section. All errors are my own. 


\section{Introduction}

One of the least-controversial lessons of neoclassical economics is that free trade increases aggregate welfare by efficiently allocating resources within countries. However, free trade also generates distributional conflicts: there will be winners and losers.

The arguments supporting aggregate welfare gains from trade are typically based on long-run theories where only an initial state (typically autarky) and a final state (free or lessdistorted trade) are considered, with no predictions of what happens in between. Perfect factor mobility is usually assumed and unemployment is seldom modeled. ${ }^{1}$ On the other hand, theories that emphasize distributional conflicts following trade liberalization rely on extreme assumptions regarding factor mobility in order to identify winners and losers. For example, in the long-run Hecksher-Ohlin model, with perfectly mobile factors, the winners and losers are characterized by what factors they own (e.g., skilled versus unskilled labor or labor versus capital). In the short-run Ricardo-Viner model, with immobile factors, winners and losers are characterized by their industry affiliation (e.g, import-competing versus export-oriented industries).

Meanwhile, free trade is far from being widely practiced, especially in developing countries. Even countries that implemented important trade reforms in the 1980s and 1990s, such as Brazil, Colombia and India, still have high import tariffs. The existence of distributional conflicts is indeed an important consideration limiting the adoption of free trade. Nevertheless, a considerable source of concern for policy makers is that we still lack a good understanding of how the economy will behave in the short-to medium-run in the aftermath of trade liberalization. This is important in order to determine how fast the gains from trade can be realized, and to better characterize who the winners and losers from trade liberalization are.

Perhaps surprisingly, economists are still not in a comfortable position to answer relevant policy questions such as: How long should we expect the labor market transition to last? To what extent will the potential gains from trade be mitigated due to the slow adjustment of the economy to the new free trade equilibrium? What are the characteristics of the workers who will lose the most from trade liberalization? What labor market policies are most promising for reducing adjustment costs, speeding up adjustment and compensating the losers?

This paper provides a better understanding of these issues by estimating a structural dynamic equilibrium model of the labor market. The framework adopted is closely related

\footnotetext{
${ }^{1}$ Notable exceptions are Neary (1978), Davidson, Martin and Matusz (1999), Helpman and Itskhoki (2009) and Helpman, Itskhoki and Redding (2010)
} 
to Lee (2005) and Lee and Wolpin (2006). The labor demand side is given by perfectly competitive sector-representative firms with Cobb-Douglas production functions and three factors - human capital from unskilled workers, human capital from skilled workers and physical capital. The labor supply side features overlapping generations, forward looking heterogeneous workers in several dimensions who have comparative advantage across sectors, endogenous accumulation of sector-specific experience, self-selection into sectors based on observable and unobservable components of wages and costly switching of sectors. Wages (human capital prices) are determined in equilibrium.

The model includes two important margins through which the labor market can adjust in response to trade reform. It features overlapping generations where older, possibly lessmobile workers retire, and younger, possibly more-mobile workers choose where to work for the first time. This implies an important role for younger generations: that of speeding up reallocation after trade reform. The model also includes a labor supply decision, so that workers can decide to drop out of the formal labor market when they are hit with bad shocks.

I employ simulation methods and a large panel of workers constructed from matched employer-employee data from Brazil in order to estimate the model. These data are particularly well suited to the analysis carried out in this paper due to the large sample size, the ability to follow workers over time and across industries and the ability to construct sector-specific experience for all workers.

The model's estimates imply that workers' costs of switching are on average large, but these vary tremendously across individuals with different observable characteristics (gender, education, age). This produces a very dispersed distribution of mobility costs within the population. Female, older and less educated workers, for example, face substantially higher costs of switching sectors. In line with previous research (Neal (1995)), this paper finds that sector-specific experience is imperfectly transferable across sectors, leading to additional barriers to mobility.

The estimated model is subsequently used as a laboratory for counterfactual experiments. In all the experiments, the price of the import-competing sector (High-Tech Manufacturing) faces a once-and-for-all decline in order to simulate a trade liberalization episode. I focus on this particular shock since tariffs in the High-Tech Manufacturing sector remained high (both in relative and absolute terms) despite the Brazilian trade liberalization episode of 1988-1994 (see Kume, Piani and Souza (2000)).

The findings indicate that: (1) there is a large labor market response following trade liberalization but the transition may take several years; (2) the analyses conducted highlight that the duration and magnitude of the transition are very sensitive to assumptions regarding the mobility of physical capital; (3) workers employed in High-Tech Manufacturing prior to 
the shock face substantial losses in welfare, especially the unskilled and the young; (4) adjustment costs - defined as the fraction of the potential gains from trade that are lost due to the slow and costly adjustment - are substantial; (5) costs of mobility are more important than sector-specific experience in explaining the slow adjustment of the labor market, at least when the shock affects the High-Tech Manufacturing sector; (6) retraining workers initially employed in the adversely affected sector reduces welfare losses incurred by these workers and may increase aggregate welfare; and (7) a moving subsidy that covers switching costs is more promising in compensating workers initially employed in the affected sector, although at the expense of higher welfare adjustment costs.

This paper contributes to the active literature that studies the impact of trade openness on labor markets. This has been a very active area of research in recent years. From a theoretical perspective, this literature focuses on the impact of trade openness on unemployment and inequality using search and matching models (Davidson, Martin and Matusz (1999), Helpman, Itskhoki and Redding (2010)); on how differences in labor market rigidities matter for the pattern of comparative advantage across countries (Cuñat and Melitz (2009), Helpman and Itskhoki (2009)); and on how to compensate losers from trade liberalization (Davidson and Matusz (2006)). From an empirical perspective, this literature focuses on the impact of trade on wages within heterogeneous-firms trade models (Verhoogen (2008) and Amiti and Davis (2008)), the exporter wage premium (Frías, Kaplan and Verhoogen (2009)) and the study of trade-induced labor market dynamics and its implications for welfare (Menezes-Filho and Muendler (2007), Kambourov (2009), Artuç, Chaudhuri and McLaren (2010), Artuç (2009), Cosar (2010) and Cosar, Guner and Tybout (2010)).

My paper is most related to Artuç, Chaudhuri and McLaren (2010), Artuç (2009), and Cosar (2010). Artuç, Chaudhuri and McLaren (2010) study inter-sectoral labor adjustment within a structural dynamic model of the labor market with competitive product and factor markets. Workers face mobility costs in order to switch sectors and are all homogeneous, apart from idiosyncratic preference shocks for sectors. The current paper estimates a model similar in spirit to that paper, but incorporates several important features, some of which were shown in the literature to be crucial in explaining the inter-sectoral wage structure, which is key for the identification of mobility costs. For example, workers are allowed to endogenously accumulate sector-specific experience, which may itself be an important additional barrier to mobility. In addition, the introduction of a rich set of worker heterogeneity in my model allows for the study of how trade-induced sectoral price changes interact with workers' demographic characteristics such as age and education. Most importantly, my model accounts for self-selection into sectors based on unobservable ${ }^{2}$ wage shocks and intro-

\footnotetext{
${ }^{2}$ From the econometrician's perspective.
} 
duces a non-market choice. Heckman and Sedlacek (1985 and 1990) show that correcting for self-selection into sectors based on unobservable components of wages as well as allowing for a non-market choice to workers are crucial for explaining the inter-sectoral wage structure.

Artuç (2009) extends Artuç, Chaudhuri and McLaren (2010) in order to analyze how trade reform differentially impacts older and younger workers. However, the empirical strategy pursued in his paper implicitly abstracts from worker self-selection into sectors based on unobservable components of wages. ${ }^{3}$ In addition, Artuç (2009) does not allow for a nonmarket option; as I show in my paper, the presence of the non-market option has important implications for the effects of trade liberalization on young versus old workers - at least in the Brazilian data.

Cosar (2010) studies labor adjustment following trade reform by calibrating a two-sector, small, open-economy model with overlapping generations, labor market search and matching, and sector-specific human capital accumulated through learning-by-doing. By simulating a trade-induced price shock in one sector, his calibrated model predicts an extremely slow adjustment of the labor market. Cosar then shows that the main factor accounting for the slow adjustment is sector-specific experience. However, in his model, sector-specific experience is not transferable across sectors. Workers who switch sectors start their new jobs with no sector-specific experience. The type of labor market models we study differ in several dimensions, but more importantly, the model in my paper allows for sector-specific experience to be transferable across sectors, though imperfectly, with the degree of transferability being estimated based on the Brazilian data. My results suggest much faster adjustment and a much smaller influence of sector-specific experience on the speed of adjustment. Finally, Cosar also uses his model in order to assess the distributional and efficiency properties of different labor market policies following trade reform. The model in my paper does not feature the externalities emphasized in Cosar's, therefore our analyses regarding labor market policies should be seen as complementary.

The paper is organized as follows. In Section 2, I outline the model. Section 3 describes the data used in the estimation. Section 4 provides a detailed presentation of the estimation procedure. In Section 5, I present and discuss the estimation results. Section 6 presents the description and analysis of the counterfactual experiments. Finally, I conclude in Section 7.

\footnotetext{
${ }^{3}$ In the actual model presented in Artuç (2009), workers do self-select into sectors based on unobservable shocks in wages. However, these selection effects are not taken into account in the derivation of a key equation of the paper, on which the empirical strategy is based. If one takes into account self-selection based on unobservables, one loses the closed form solution for equilibrium wages, so that the empirical strategy pursued in the paper must be redesigned.
} 


\section{Model}

The framework in this paper is closely related to papers by Heckman and Sedlacek (1985), Lee (2005) and Lee and Wolpin (2006). In short, it is an equilibrium dynamic version of the Roy Model (Roy (1951), Heckman and Honoré (1990)). The economy is divided into four productive sectors and a non-productive Residual Sector, indexed as follows: (0) Residual Sector; (1) Agriculture and Mining (Primary); (2) Low-Tech Manufacturing; (3) High-Tech Manufacturing; and (4) Non-Tradeables.

For the time being, let us think of the Residual Sector as home production or an "out of the labor force" decision. In fact, home production is only one component of the Residual Sector, but I postpone a detailed definition of the Residual Sector to the next section, when I present and discuss the data.

The production side of the model has sector-representative firms. Factors of production are human capital from unskilled (of lower educational achievement) workers, human capital from skilled (of higher educational achievement) workers and physical capital. Firms' decisions yield the demand for each type of human capital in each sector.

The human capital supply side has forward-looking heterogeneous workers supplying human capital to the sector-representative firms. Workers have comparative advantage: the amount of human capital they can supply differ across sectors. For example, a worker can be better in shoe making than she is in car making or vice versa. However, a worker can supply

human capital to one sector at the most. Sector-specific human capital has a deterministic component that depends on individual characteristics such as education, age and sectorspecific experience, but also depends on an idiosyncratic shock. At each period, a worker draws new idiosyncratic shocks for the amount of human capital she can supply to each sector, and chooses to work in the sector in which her present value utility is maximized. If the worker decides to work in a different sector than that of the last period, a switching cost must be incurred. Finally, new generations come to the labor market and old generations retire each year. The decisions of individual workers aggregate to the supply of human capital for each sector. Human capital prices are determined in equilibrium - they equate aggregate demand to aggregate supply of each type of human capital in each sector. 


\subsection{Production}

Production is undertaken by sector level representative firms with Cobb-Douglas production functions. Value added ${ }^{4}$ in sector $s$ is given by:

$$
Y_{t}^{s}=p_{t}^{s} A_{t}^{s}\left(H_{t}^{0, s}\right)^{\alpha_{t}^{0, s}}\left(H_{t}^{1, s}\right)^{\alpha_{t}^{1, s}}\left(K_{t}^{s}\right)^{1-\alpha_{t}^{0, s}-\alpha_{t}^{1, s}}
$$

Where $p_{t}^{s}$ is the price of output of sector $s$ at time $t ; A_{t}^{s}$ is the productivity of sector $s$ at time $t ; H_{t}^{0, s}$ is the aggregate human capital employed in sector $s$ at time $t$ coming from unskilled workers; $H_{t}^{1, s}$ is the aggregate human capital employed in sector $s$ at time $t$ coming from skilled workers; and $K_{t}^{s}$ is the aggregate physical capital employed in sector $s$ at time $t$.

Firms act competitively, and hence demand for the two types of human capital and physical capital are given by:

$$
\begin{aligned}
r_{t}^{0, s} & =\alpha_{t}^{0, s} \frac{Y_{t}^{s}}{H_{s t}^{0}} \\
r_{t}^{1, s} & =\alpha_{t}^{1, s} \frac{Y_{t}^{s}}{H_{s t}^{1}} \\
r_{t}^{K, s} & =\left(1-\alpha_{t}^{0, s}-\alpha_{t}^{1, s}\right) \frac{Y_{t}^{s}}{K_{t}^{s}}
\end{aligned}
$$

Where $r_{t}^{0, s}$ is the price of one unit of human capital in sector $s$ at time $t$ coming from unskilled workers; $r_{t}^{1, s}$ is the price of one unit of human capital in sector $s$ at time $t$ coming from skilled workers; and $r_{t}^{K, s}$ is the rental price of one unit of physical capital in sector $s$. This rental price can differ across sectors, depending on what assumptions are made about the mobility of physical capital.

In (1) unskilled and skilled human capital are complementary in order to allow trade liberalization to affect the skill premium, i.e., the ratio $\frac{r_{t}^{1, s}}{r_{t}^{0, s}}$.

\subsection{Workers}

Workers have instantaneous utility flow given by: ${ }^{5}$

\footnotetext{
${ }^{4}$ The emphasis on value added is based on available data from the Brazilian National Accounts.

${ }^{5}$ The Cobb-Douglas utility function for consumption is convenient since it implies that decisions regarding which sector to work in does not depend on relative prices, only on relative real wages and the value of the Residual Sector.
} 


$$
U\left(s_{0}, s_{1}, \mathbf{C}\right)=w^{0} \times I\left(s_{1}=0\right)+\left(\prod_{k=1}^{4}\left(C^{k}\right)^{\mu^{k}}\right)-\text { Cost }^{s_{0} s_{1}}
$$

Where $s_{0}$ is the sector chosen in the previous period; $s_{1}$ is the sector chosen in the current period; $\mathbf{C}=\left(C^{1}, C^{2}, C^{3}, C^{4}\right)$ is the vector of consumption; $I($.$) is an indicator function; w^{0}$ is the utility flow of choosing the Residual Sector; $\mu^{k}$ is the expenditure share in sector $k$ with $\sum_{k=1}^{4} \mu^{k}=1$; and $\operatorname{Cost}^{s_{0} s_{1}}$ is the disutility of switching from sector $s_{0}$ to sector $s_{1}$.

A worker chooses in which sector to work at age $a$ and how much to consume in order to maximize the expected present value of her utility. There is no saving nor borrowing. Wages that are received when a worker is of age $a$ must be totally consumed in that year. If the worker chooses the Residual Sector, she receives no wages and hence cannot consume any produced goods. For the time being, it can be thought of as the worker enjoying leisure and receiving utility $w^{0}$ from it. The only way of enjoying utility from leisure in the model is by choosing the Residual Sector.

Workers enter the labor market at age 25 and retire at age $60 .{ }^{6}$

A worker's life cycle problem when she is of age $a$ is formally given by:

$$
\left\{\begin{array}{c}
\underset{\left\{s_{a}, C_{a}\right\}_{\tau=a}}{\operatorname{Max}} \sum^{A} \rho^{\tau-a} E_{a} U\left(s_{\tau-1}, s_{\tau}, C_{\tau}\right) \\
\text { s.t. } \sum_{i=1}^{4} p_{i \tau} C_{i \tau}=\sum_{j=1}^{4} w_{\tau}^{j} d\left(j=s_{\tau}\right) \forall \tau=a, \ldots, A
\end{array}\right.
$$

Where $\rho$ is the discount factor; $w_{\tau}^{s}$ is the nominal wage offer from sector $s$ to the worker when she is of age $\tau ; p_{\tau}^{s}$ is the price of sector $s$ output when the worker has age $\tau$.

The problem above is equivalent to first choosing where to work at age $a\left(s_{a}\right)$ :

$$
\underset{\left\{s_{a}\right\}}{\operatorname{Max}} \sum_{\tau=a}^{A} \rho^{\tau-a} E_{a}\left(w_{\tau}^{0} \times I\left(s_{\tau}=0\right)+\frac{w_{\tau}^{s_{\tau}}}{\left(\prod_{k=1}^{4}\left(p_{\tau}^{k}\right)^{\mu^{k}}\right)} I\left(s_{\tau} \neq 0\right)-\operatorname{Cost}^{s_{\tau-1} s_{\tau}}\right)
$$

And then choosing the optimal consumption basket at each point in time.

\footnotetext{
${ }^{6}$ RAIS, the dataset used in this paper and introduced in the next section, only includes information on individuals who have worked at least once in the formal sector. Information on educational decisions is not available. For this reason, the model has workers starting at age 25 , since at that age educational decisions should be complete for the vast majority of the population.
} 


$$
\left(\prod_{k=1}^{4}\left(p_{\tau}^{k}\right)^{\mu^{k}}\right) \text { is the Cobb-Douglas price index, and hence } \frac{w_{\tau}^{s}}{\left(\prod_{k=1}^{4}\left(p_{\tau}^{k}\right)^{\mu^{k}}\right)} \text { is the real wage }
$$

the worker would receive would she choose to work in sector $s$ at age $\tau$. From now on, all variables will be expressed in real terms.

I now model each component of equation (5). Variables will be indexed as follows: $i$ : individual; $a$ : age; $s$ : sector; $t$ : time (year); and $\operatorname{skill}(i)$ : skill level of individual $i$. Skill level can take the values 0 or 1 (unskilled or skilled).

The level of education is divided in four categories as follows: (1) From Illiterate to Primary School Graduate; (2) From Some Middle School to Some High School; (3) High School Graduate; (4) At Least Some College.

Worker $i$ is labeled skilled $(\operatorname{skill}(i)=1)$ if she has education level 3 or 4 (high school graduate or higher) and unskilled $(\operatorname{skill}(i)=0)$ otherwise (less than high school).

\subsubsection{Wages}

Wages are modeled in the same way as in Heckman and Sedlacek (1985), Lee (2005) and Lee and Wolpin (2006). This specification for wages has been referred to, in the Labor Economics literature, as the Ben-Porath-Griliches specification of the wage function. ${ }^{7}$ In the International Trade literature, this specification was used by Ohnsorge and Trefler (2007).

The wage $w_{i a t}^{s}$ in sector $s$ offered to worker $i$ of age $a$ at time $t$ is given by the price of human capital in sector $s$ at time $t$ times the amount of human capital the worker can supply to that sector.

$$
w_{\text {iat }}^{s}=\left\{\begin{array}{c}
r_{t}^{0, s} h_{\text {iat }}^{0, s} \text { if } \operatorname{skill}(i)=0 \\
r_{t}^{1} h_{\text {iat }}^{1, s} \text { if } \operatorname{skill}(i)=1
\end{array}\right.
$$

The amount of human capital worker $i$ of age $a$ at time $t$ can supply to sector $s$ depends on characteristics such as gender and education dummies, age and sector-specific experience accumulated in each of the four productive sectors up to time $t-1\left(\right.$ Exper $_{i k t}$ for $\left.k=1, \ldots, 4\right)$. It also depends on an idiosyncratic component $\varepsilon_{i t}^{s}$, which is unobserved by the econometrician,

\footnotetext{
${ }^{7}$ See Griliches (1977) and Willis (1986).
} 
but observed by the worker. The human capital production functions are given by:

$$
\begin{aligned}
& h_{i a t}^{0, s}=\exp \left(\begin{array}{c}
\beta_{1}^{s} \text { Female }_{i}+\beta_{2}^{s} I\left(\text { Educ }_{i}=2\right)+\beta_{4}^{s}(a-25)+ \\
\beta_{5}^{s}(a-25)^{2}+\sum_{k=1}^{4} \beta_{5+k}^{s} \text { Exper }_{i k t}+\varepsilon_{i t}^{s}
\end{array}\right) \\
& h_{i a t}^{1, s}=\exp \left(\begin{array}{c}
\beta_{1}^{s} \text { Female }_{i}+\beta_{3}^{s} I\left(E d u c_{i}=4\right)+\beta_{4}^{s}(a-25)+ \\
\beta_{5}^{s}(a-25)^{2}+\sum_{k=1}^{4} \beta_{5+k}^{s} \text { Exper }_{i k t}+\varepsilon_{i t}^{s}
\end{array}\right)
\end{aligned}
$$

The parameter vector $\boldsymbol{\beta}^{s}$ is the same for both types of human capital. I allow for workers within a specific level of skill but with a higher education level to be more productive, everything else equal. For example, everything else equal, within skill level 0, workers with education level 2 are more productive than workers with education level 1 . The only difference between the two equations in (7) is in the education coefficient: $\beta_{2}^{s}$ for the unskilled workers and $\beta_{3}^{s}$ for the skilled workers.

It is important to call attention to the fact that the human capital production functions in (7) allow for skills acquired in sector $i$ to be transferable to sector $j$. The degree of transferability is given by the parameters $\beta_{6}^{s}$ to $\beta_{9}^{s}$ and will be estimated.

Note that the human capital production functions do not have intercepts. We cannot separately identify the intercepts in the human capital production functions and the level of the human capital prices. Consequently, I normalize the human capital intercepts to zero.

\subsubsection{Value of the Residual Sector}

The value of the Residual Sector $w_{i a t}^{0}$ for worker $i$ of age $a$ at time $t$ depends on her observable characteristics (gender and education dummies, age) and on an idiosyncratic component $\varepsilon_{i t}^{0}$, which is unobserved by the econometrician, but observed by the worker.

$$
w_{i a t}^{0}=\exp \left(\begin{array}{c}
\gamma_{0}+\gamma_{1} \text { Female }_{i}+\sum_{l=2}^{4} \gamma_{l} I\left(\text { Educ }_{i}=l\right)+ \\
\gamma_{5}(a-25)+\gamma_{6}(a-25)^{2}
\end{array}\right)+\varepsilon_{i t}^{0}
$$

The value of the Residual Sector is not observed in the data, but can be estimated using information on wages in the different sectors, on the fraction of workers who choose the Residual Sector and transition rates in and out of that sector. More details on identification are provided in Section 4.2 .

Finally, the vector of idiosyncratic shocks $\left(\varepsilon_{i t}\right)$ for the productive and Residual Sectors 
are independent across $i$ and $t$ and drawn from a normal distribution. ${ }^{8}$

$$
\varepsilon_{i t} \sim N(0, \Sigma)
$$

Where $\Sigma$ is a diagonal matrix.

It is convenient to note that the model has two sources of mobility across sectors. First, workers face sector-specific idiosyncratic shocks in their sector-specific human capital production functions and that generates two-way flows: from sector $i$ to sector $j$ and from sector $j$ to sector $i$. Second, variation in the human capital prices will make sectors more or less attractive to all workers, leading to net flows between sectors. These two features of the model will generate gross flows in excess of net flows, which is a stylized fact emphasized by Artuç, Chaudhuri and McLaren (2010) and which is also present in the data used in the current paper (see next Section).

\subsubsection{Costs of switching sectors (mobility costs)}

The costs of switching sectors, or mobility costs, for worker $i$ of age $a$ are given by equation (9), and depend on gender and education dummies, age, and the sectors of origin $s$ and destination $s^{\prime}$.

$$
\begin{aligned}
& \text { Cost }_{i a}^{s s^{\prime}}=\exp \left(\begin{array}{c}
\varphi^{s s^{\prime}}+\kappa_{1} \text { Female }_{i}+\sum_{l=2}^{4} \kappa_{l} I\left(E^{2} d u c_{i}=l\right)+ \\
\kappa_{5}(a-25)+\kappa_{6}(a-25)^{2}
\end{array}\right) s \neq s^{\prime}, s^{\prime} \neq 0 \\
& \text { Cost }_{i a}^{s s^{\prime}}=0 \quad s=s^{\prime}, s^{\prime}=0
\end{aligned}
$$

Since in the model costs of switching sectors are utility costs, the interpretation of these costs is that workers have a preference for the status quo and/or face psychological costs when switching sectors. These costs may also capture other barriers to mobility that are not included in the model such as geographic mobility costs, search and matching frictions, and/or firms' firing and hiring costs (see Kambourov (2009)). ${ }^{9}$

Intuitively, the costs of switching are a measure for the inability of workers to arbitrage wage differentials away. Consider a two-sector economy and suppose worker $i$ is initially working in sector 1. Suppose further that, for worker $i$, the expected present value of

\footnotetext{
${ }^{8} \mathrm{~A}$ version of the paper where the unobservable component of wages and value of the Residual Sector $\varepsilon_{i t}$ has both a fixed and a time varying component is under preparation.

${ }^{9} \mathrm{~A}$ micro-foundation study of these costs is an important avenue for future research. In this paper costs of mobility should be interpreted purely as a measure of workers' inability to arbitrage wage differentials. It is revealed using information on wage differentials, transition rates and the structure of the model. More details on identification will be provided in Section 4.2
} 
working in sector 2 is higher than the expected presented value of working in sector 1 - that is, $V_{i, 2}>V_{i, 1}$. The cost of switching sector 1 for 2 for worker $i$ is given by the difference $V_{i, 2}-V_{i, 1}$ which makes her indifferent to move. When computing $V_{i, 1}$ and $V_{i, 2}$, the worker knows that by moving from sector 1 to sector 2 , her sector 1 -specific experience is not going to be fully transferable to her human capital in sector 2 and takes that into account.

It is important to notice that the model features two distinct sources of barriers to mobility. One works directly through direct wage effects of moving: sector-specific experience is not fully transferable across sectors. ${ }^{10}$ The other works through the inability of arbitraging wage differentials, taking sector-specific experience into account, i.e., mobility costs.

\subsubsection{Expectations}

In order to choose where to work at age $a$ and time $t$, a worker must form expectations on future wage offers and on future values for the Residual Sector (see equation (5)). I adopt a simplifying assumption regarding how workers form expectations regarding future human capital prices. Workers are assumed to behave myopically in the sense that they think that the equilibrium human capital prices that are formed at time $t$, will persist forever, with no uncertainty. At time $t+1$, new equilibrium human capital prices are formed and at this point, workers think these newly formed prices will persist forever, and so on.

In principle, it would be possible to make more sophisticated assumptions regarding expectations. One could impose expectations in the spirit of Krusell and Smith (1998), where workers use only a few moments in order to form expectations about the future, but these expectations must be consistent with the outcomes produced by the model. A version of this approach was developed by Lee and Wolpin (2006), where they imposed that workers predict future human capital prices using a $V A R$ relating current human capital prices to current sectoral prices, past human capital prices and past physical capital rental prices. The $V A R$, used by the workers in order to make predictions about the future, was imposed to be consistent with the stochastic process for human capital prices generated by the model. This would be a desirable benchmark for this paper. The obstacle for following this route is that I use only 11 years of data in order to estimate the model, and a simple $V A R$ with only current human capital prices would have more parameters than data points. Even by imposing structure on the $V A R$, we would be left with very few degrees of freedom. Moreover, the fixed point computation necessary to make expectations consistent with the model outcome makes estimation much more expensive.

Consequently, given myopic expectations, expectations in (5) are computed only with respect to future idiosyncratic shocks, which are unknown at the time the sectoral decision

\footnotetext{
${ }^{10}$ This is what the data actually reveal, see Section 5 .
} 
is made.

\subsubsection{Bellman Equation}

The state space $\Omega_{\text {iat }}$ of worker $i$ of age $a$ at time $t$ is given by all variables that are relevant for the determination of the current value of the Residual Sector, the real wage the worker would get in any of the productive sectors, the costs that must be incurred when switching sectors and any other variable relevant for the formation of expectations. Given the myopic assumption on expectations, these include: gender, level of education, history of sectors of activity, current real human capital prices and current idiosyncratic shocks.

$$
\Omega_{\text {iat }}=\left\{\begin{array}{l}
\left\{t, \text { Female }_{i}, \text { Educ }_{i}, a, d_{i, t-9}, \ldots, d_{i, t-1}, r_{t}^{0,1}, \ldots, r_{t}^{0,4}, \varepsilon_{i t}^{0}, \ldots, \varepsilon_{i t}^{4}\right\} \text { if } \operatorname{skill}(i)=0 \\
\left\{t, \text { Female }_{i}, \text { Educ }_{i}, a, d_{i, t-9}, \ldots, d_{i, t-1}, r_{t}^{1,1}, \ldots, r_{t}^{1,4}, \varepsilon_{i t}^{0}, \ldots, \varepsilon_{i t}^{4}\right\} \text { if } \operatorname{skill}(i)=1
\end{array}\right.
$$

Note that I have included in $\Omega_{\text {iat }}$ the history of sectors of activity only up to 9 lags $\left(d_{i, t-9}, \ldots, d_{i, t-1}\right)$. I assume that only experience accumulated in a window of 9 years is relevant for the determination of human capital. The reason behind this assumption comes from data limitations. The sample used in estimation starts with data for 1995. The data from 1986 to 1994 (i.e, 9 lags) are used in order to construct workers' sector-specific experience variables in 1995 or when they first enter the sample. In other words, the data from 1986 to 1994 are used in order to construct workers' initial conditions.

The Bellman Equations for problem (5) is given below by equations (11)-(12).

$$
\begin{gathered}
V_{a}\left(\Omega_{a t}\right)=\max _{s \in\{0,1, \ldots, 4\}}\left\{V_{a}^{s}\left(\Omega_{a t}\right)\right\} \\
V_{a}^{s}\left(\Omega_{a t}\right)=\left\{\begin{array}{c}
w_{t}^{s}-\operatorname{Cost}^{\left(s_{a-1, t-1}\right) s}+\rho E V_{a+1}\left(\Omega_{a+1, t+1} \mid \Omega_{a t}, d_{t}=s\right) \text { for } a<60 \\
w_{t}^{s}-\operatorname{Cost}^{\left(s_{a-1, t-1}\right)} \text { for } a=60
\end{array}\right. \\
s=0,1, \ldots, 4
\end{gathered}
$$

\subsubsection{Aggregate Supply of Human Capital}

Workers solve the Bellman Equations (11)-(12) in order to decide what sector to choose at

each age $a$ and period $t$. Let $d^{s}\left(\Omega_{i a t}\right)$ be an indicator variable for whether a worker with 
state $\Omega_{\text {iat }}$ chooses sector $s$.

$$
d^{s}\left(\Omega_{i a t}\right)=I\left\{V_{a}^{s}\left(\Omega_{i a t}\right) \geq V_{a}^{s^{\prime}}\left(\Omega_{i a t}\right) \forall s^{\prime}\right\}
$$

The aggregate supply of human capital to sector $s$ at time $t$ is given by:

$$
\begin{aligned}
& \left(H_{t}^{0, s}\left(\left\{r_{t}^{0, k}\right\}_{k=1}^{4}, \widetilde{\Omega}_{t}\right)\right)_{\text {Supply }}=\sum_{a=25}^{60} \sum_{i=1}^{N_{a t}} I(\operatorname{skill}(i)=0) h_{\text {iat }}^{0, s} d^{s}\left(\Omega_{\text {iat }}\right) s=1, \ldots, 4 \\
& \left(H_{t}^{1, s}\left(\left\{r_{t}^{1, k}\right\}_{k=1}^{4}, \widetilde{\Omega}_{t}\right)\right)_{\text {Supply }}=\sum_{a=25}^{60} \sum_{i=1}^{N_{a t}} I(\operatorname{skill}(i)=1) h_{\text {iat }}^{1, s} d^{s}\left(\Omega_{\text {iat }}\right) s=1, \ldots, 4
\end{aligned}
$$

Where $N_{a t}$ is the size of cohort born at $t-a$, and $\widetilde{\Omega}_{t}$ is the collection of all active (25 to 60 years old) workers' state spaces at time $t$, excluding human capital prices.

\subsection{Labor Market Equilibrium}

Controlling for the real value added in each sector $\left\{Y_{t}^{k}\right\}_{k=1}^{4}$ (which is observed data from the Brazilian National Accounts and will be fixed throughout the estimation), the equilibrium real human capital prices are determined as the solution to:

$$
\begin{aligned}
& \left(H_{t}^{0, s}\left(\left\{r_{t}^{0, k}\right\}_{k=1}^{4}, \widetilde{\Omega}_{t}\right)\right)_{\text {Supply }}=\alpha_{t}^{0, s} \frac{Y_{t}^{s}}{r_{t}^{0, s}} \quad s=1, \ldots, 4 \\
& \left(H_{t}^{1, s}\left(\left\{r_{t}^{1, k}\right\}_{k=1}^{4}, \widetilde{\Omega}_{t}\right)\right)_{\text {Supply }}=\alpha_{t}^{1, s} \frac{Y_{t}^{s}}{r_{t}^{1, s}} \quad s=1, \ldots, 4
\end{aligned}
$$

Throughout the estimation, I impose that the model generates the real value added series $\left\{Y_{t}^{k}\right\}_{k=1}^{4}$ and the unskilled and skilled workers' wage bill series $\left\{\alpha_{t}^{0, s} Y_{t}^{k}\right\}_{k=1}^{4}$ and $\left\{\alpha_{t}^{1, s} Y_{t}^{k}\right\}_{k=1}^{4}$ (which are all observed data) with equality.

At this point, it is important to note that given the Cobb-Douglas production functions and the assumptions made on how workers form expectations, we do not need to make any assumptions about the mobility of physical capital in order to estimate the parameters of the model.

Given parameter values for the human capital production functions, value of the Residual Sector and for the costs of switching functions, we can compute human capital demand (right hand side of equation (15)) and human capital supply (left hand side of equation (15)) by simulating the model, and solving for the equilibrium human capital prices without the need for physical capital rental prices.

Two other observations about estimation are now timely. First, note that, since I control 
for $\left\{Y_{t}^{k}\right\}_{k=1}^{4}$, and given the assumptions on expectations, I do not need to recover neither the prices $p_{t}^{s}$ nor the productivity terms $A_{t}^{s}$. Second, not only do we not have to make assumptions regarding the mobility of physical capital, but also I do not need to model how physical capital is being accumulated. Given the Cobb-Douglas assumption on the production functions and the assumptions on expectations, all the information about the human capital demand side that is relevant for estimation is contained in $\left\{Y_{t}^{k}\right\}_{k=1}^{4}$.

Additional structure on the model will have to be imposed when I implement the counterfactual experiments, but I postpone these details to Section 6 .

\section{Data}

\subsection{A Panel of Workers (1995 to 2005)}

The data used in this paper comes from the Relação Anual de Informações Sociais (RAIS), a matched employer-employee dataset assembled by the Brazilian Ministry of Labor every year since 1986. Each year the universe of Brazilian firms are required by law to file information about both the firm as well as about each of its employees to the Ministry of Labor. These data are collected in order to fulfill two main objectives: (1) for the government to generate statistics about the labor market; and (2) to serve as the main source of information on whether a certain employee is eligible to receive the abono salarial, which consists of one extra minimum yearly wage payment provided by the government.

The data consist of job entries identified by both a worker ID number $(P I S)$ and a firmplant registration number $(C N P J)$. These identifiers are unique and do not change over time, which allow us to track workers over time and across firms and plants. Each job entry comes with information regarding the firm-plant pair where the worker was employed. There is information on geographic location, 5-digit level NAICS industry, capital ownership and other variables. At the worker level, we have information on gender, age, level of education, monthly wage, number of hours in the contract, tenure at the firm, occupation, month of accession into the job (if accession occurred during the current year), month of separation (if any) and other variables.

In order to track workers over time and across sectors, and in order to construct sectorspecific experience variables, I constructed a panel of workers by first listing all the identifiers that appear in the data between 1995 and 2005. I then selected a random sample of $1 \%$ of distinct worker ID numbers at random (approximately 600,000 workers). These are the individuals that are followed in the panel. Since RAIS has data available since 1986, I used the observations from 1986 to 1994 in order to construct the experience variables that will 
enter the initial conditions used in the simulation as well as in the estimation of the auxiliary models used for the estimation of the structural parameters. If I did not use the years 1986 to 1994, I would not be able to recover the experience variables of individuals who first enter the constructed panel in 1995.

Since the model assumes that a worker can supply her skills to a single sector (job) each year, I select a single job entry for each worker in each year. If a worker has multiple jobs in a given year, the job with highest hourly wage is selected. Hourly wages are computed by dividing the monthly wage by the number of hours in the contract. In this paper wages are actually hourly wages, since in the context of the model there is no full-or part-time decision and all workers are assumed to work full-time.

Since this is a census of the Brazilian formal labor market only, we lose track of workers who do not hold a job in the formal sector in a given year. In a given year, we are unable to observe a worker in RAIS if she is unemployed, out of the labor force, informally employed or even self-employed. Because workers' ID numbers are unique, we can keep tracking her once she returns to a job in the formal sector. Consequently, movements in and out of the data set are quite frequent and for a large portion of workers. In order to accommodate this feature of the data, I included a Residual Sector into the model, which represents the complement of formal sector employment. Transitions to the Residual Sector are rational and voluntary, as outlined in the model.

The advantages of using such data are threefold. First, we have the ability to construct a panel of workers and track them over time and across sectors. Second, by using past rounds of the data, we can recover initial conditions (sector-specific experience) for all workers, which allows us to control for them in the estimation. Third, we have a very large sample size, which will lead to high precision in the estimates.

\subsection{Aggregate Data}

Using the Brazilian National Accounts, it was possible to construct value added series for each of the aggregate sectors used in this paper. Although data on the rental price of physical capital is not used in the estimation procedure, I will need these when I simulate the model. Aggregate capital stock series were constructed in Morandi (2004) and are available for download at www.ipeadata.br. Unfortunately, there are no available series that would allow for the construction of capital stock series at the industry level. Economy-wide returns to capital were calculated as: $r_{t}^{K}=\frac{\text { Capital Share } \times \text { Value Added }}{\text { Capital Stock }}$.

Although the Brazilian National Accounts provide information on the economy-wide wage bill, the labor share calculated as $\frac{\text { Wage Bill }}{\text { Value Added }}$ fluctuates at around 0.4. Gollin (2002) 
suggests that the labor income that comes from National Accounts are most likely to be badly downward biased since they fail to correctly take into account the incomes of self-employed or informal workers. By correcting for self-employment he finds that among the countries he studies, he is able to reduce the dispersion of wage bill shares from 0.05-0.8 to 0.65-0.8. I follow this advice and impose that the economy-wide wage bill share in Brazil is equal to 0.65 and constant over time. Hence, the physical capital share used in the calculation of returns to capital is calibrated at 0.35 .

In order to get sector-specific wage bill shares, the relative sectoral wage bill shares are fixed as in the data and are inflated so that the economy-wide wage bill equals 0.65 times Value Added.

All quantities are expressed in terms of $2005 \mathrm{R} \$$ by deflating the nominal quantities using the Índice Nacional de Preços ao Consumidor (INPC).

\subsection{Some Features of the Data}

The four (productive) aggregate sectors used in this paper are: 1) Agriculture and Mining; 2) Low-Tech Manufacturing; 3) High-Tech Manufacturing and 4) Non-Tradeables. In principle, the model allows for a much finer partition of the economy, but increasing the number of sectors will quickly make the estimation of the model computationally infeasible.

This paper focuses on inter-sectoral reallocation following a trade shock, and it is natural to separate the manufacturing sector into Low-Tech - a sector in which Brazil has a comparative advantage due to its abundance of low-skilled workers - and High-Tech - a sector in which Brazil has a comparative disadvantage and where import tariffs are higher during the sample period (1995 to 2005), see Kume, Piani and Souza (2000). Agriculture and Mining is also an important export-oriented sector in Brazil.

The division of Manufacturing into Low and High-Tech was based on the OECD Science Technology and Industry Scoreboard 2001 report "Towards a Knowledge Based Economy." In this report, the OECD classifies industries according to their technology intensity. I classified as Non-Tradeables all the sectors with 2-digit NAICS classification greater than or equal to 40, which include the following broadly-defined sectors: Retail and Wholesale Trade, Utilities, Transportation, Government and Services. Table 1 details how the 2-digit NAICS industries were separated into the four aggregate sectors this paper works with.

Figure 1 shows the employment shares across these four sectors. The shares of Agriculture and Mining vary between 5\% and 6\%, High Tech Manufacturing between $4 \%$ and 6\%, LowTech Manufacturing between $14 \%$ and $16 \%$ and Non-Tradeables between $74 \%$ and $76 \%$. A closer look at these shares reveals that their importance has changed over time. Figure 2 
plots the changes in relative importance of each of these sectors over time. In other words, it plots

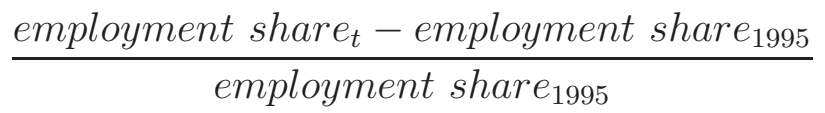

We can see that the Agriculture/Mining and Non-Tradeables sectors have gained importance between 1995 and 2005, whereas the opposite happened to both manufacturing sectors. Hence, Figure 2 shows that there appears to be some reallocation taking place between these four sectors during the sample period, possibly due to the slow response to both the trade reform implemented in 1990 and Mercosur.

Table 2 presents median hourly wages in the overall economy as well as in each of the four sectors in terms of $2005 \mathrm{R} \$ .^{11}$

Table 3 shows the matrix of yearly flows from 1995 to 2005, averaged out. The matrix shows that, although net flows between sectors do not appear to be that large in Figure 1, gross flows are quite important, with a mass of workers entering and leaving the same sectors. We can also see the importance of the Residual Sector, with important flows into this sector coming from all other sectors. Transitions to the Residual Sector are most frequent if a worker comes from Agriculture and Mining, with 17\% of workers in that sector going to the Residual Sector every year. The productive sector that appears to receive larger inflows of workers is the Non-Tradeables sector, but this is also the largest sector. What is also important to observe from this matrix is the high persistence in the sector of origin. The diagonal of the matrix has numbers between $75 \%$ and $86 \%$, suggesting both the importance of sector-specific experience as well as costs of switching sectors, key ingredients in the model outlined in the previous section.

In order to have an idea of how wage differentials have evolved over the sample periods, I estimated the following log-wage regressions for each year $t=1995, \ldots, 2005$ :

$$
\begin{aligned}
\log w_{i t}= & \sum_{k=1}^{4} \alpha_{k}^{t} \cdot d_{i k t}+\beta_{1 t} \text { Female }_{i}+\sum_{l=2}^{4} \beta_{l t} \text { Educ }_{l}+\beta_{5 t}\left(\text { Age }_{i}-25\right)+ \\
& \beta_{6 t}\left(\text { Age }_{i}-25\right)^{2}+\sum_{l=1}^{4} \beta_{(6+l) t} \text { Exper }_{i l t}+\varepsilon_{i t}
\end{aligned}
$$

$d_{i k t}$ is a dummy indicating whether worker $i$ is at sector $k$ at period $t$. Figure 3 plots the evolution of the demeaned sector intercepts $\alpha_{s}^{t}-\sum_{k=1}^{4} e m p_{k t} \alpha_{k}^{t}$, where $e m p_{k t}$ is the employment share of sector $k$ at year $t$. There are three things to note. First, there is a

\footnotetext{
${ }^{11}$ The average exchange rate between the Brazilian Real ( $\mathrm{R} \$$ ) and the US Dollar (US\$) was $2.43 \mathrm{R} \$ / \mathrm{US} \$$ in 2005 .
} 
considerable dispersion in wage differentials, with High-Tech paying the most and Agriculture/Mining paying the least, even after controlling for observables. Second, this dispersion has decreased between 1995 and 2005, mainly due to an upward trend in relative wages in Agriculture/Mining and a downward trend in relative wages in High-Tech Manufacturing. Third, there is very little volatility of wage differentials, at least around the trends.

Given the third observation above, introducing uncertainty in the way workers form expectations is unlikely to produce significantly different results, given the low volatility of wage differentials in the data. A seemingly more important modification of the myopic assumption employed in this paper, would be to allow for trends in the human capital prices. However, it is unclear how one would proceed with this route, especially when one conducts the counterfactual simulations.

\section{Estimation}

In this Section, I outline the Indirect Inference ${ }^{12}$ method that was used in the estimation. Moreover, I discuss what features of the data will be used in the Indirect Inference estimation procedure, the so-called "auxiliary models". Finally, I discuss how the model is econometrically identified.

\subsection{Indirect Inference}

The estimation method that will be employed in this paper is Indirect Inference (Gouriéroux and Monfort (1996)). In this method, we first choose a set of auxiliary models that provide a detailed statistical description of the data. The objective of these auxiliary models is to attempt to capture as much information as possible concerning moments and statistical relationships the researcher believes are important to be matched by the structural model. It is also important that the choice of auxiliary models allows for the structural parameters to be identified. More details on identification and the selection of the auxiliary models are provided in Section 4.2 .

Here is how I proceed with the estimation.

1. Obtain the time varying human capital shares $\alpha_{t}^{s}$ using the skill level specific wage bills and value added $Y_{t}^{s}$ for each sector $s=1, \ldots, 4$. Remember that I impose the economy-wide skill share to be equal to 0.65 , so the total wage bill must be corrected upwards.

\footnotetext{
${ }^{12}$ I opted to use Indirect Inference in this paper because the likelihood function does not have a closed-form solution. Consequently, for each individual in the sample, 5-dimensional integrals without closed form must be numerically computed for each guess of the parameter set, making maximum likelihood computationally much more demanding than Indirect Inference.
} 
2. Impose the inter-temporal discount factor to $\rho=0.95$.

3. Estimate the auxiliary models with data from the panel of workers. Let $\widehat{\delta}$ denote the estimates of these models all stacked up in a single vector. This vector will be fixed throughout the estimation procedure.

4. Extract initial conditions from the panel of workers. The initial conditions consist of the empirical joint distribution of age, gender, education level and sector-specific experiences as found in the data. In 1995, I will have initial conditions for individuals aged 25 to 60 years old and after that, from 1996 to 2005, I will only have initial conditions for entering generations at the age of 25 (the age of labor market entry in the model). 1,000 individuals for each cohort and skill level (skilled or unskilled) are sampled from the data, and adequately weighted by the size of their corresponding cohort and skill level. These are the individuals who will be used for simulating the model.

Steps 5 to 9 are embedded in an optimization routine.

5. Given a set of structural parameters $\Theta$, solve the Bellman equations, that is, compute the $E V_{a}($.$) functions in (12) for each age a$ at each point of the state space. Appendix A gives the details on how the Bellman equations are solved.

6 . For $t=1995, \ldots, 2005$ compute, by simulating the economy parametrized by $\Theta$, the equilibrium vectors of human capital prices $\left\{r_{t}^{0, k}\right\}_{k=1}^{4}$ and $\left\{r_{t}^{1, k}\right\}_{k=1}^{4}$ that satisfy:

$$
\begin{gathered}
H_{t}^{0, s}=\sum_{a=25}^{60} \sum_{i=1}^{1000} N_{a t}^{0} h_{i a t}^{0, s} d^{s}\left(\left\{r_{t}^{0, k}\right\}_{k=1}^{4}, \widetilde{\Omega}_{i a t}\right) \quad s=1, \ldots, 4 \\
H_{t}^{1, s}=\sum_{a=25}^{60} \sum_{i=1}^{1000} N_{a t}^{1} h_{i a t}^{1, s} d^{s}\left(\left\{r_{t}^{1, k}\right\}_{k=1}^{4}, \widetilde{\Omega}_{i a t}\right) \quad s=1, \ldots, 4 \\
r_{t}^{0, s}=\alpha_{t}^{0, s} \frac{Y_{t}^{s}}{H_{t}^{0, s}} \quad s=1, \ldots, 4 \\
r_{t}^{1, s}=\alpha_{t}^{1, s} \frac{Y_{t}^{s}}{H_{t}^{1, s}} \quad s=1, \ldots, 4
\end{gathered}
$$

Where $N_{a t}^{\text {skill }}$ is the relative size of cohort with age $a$ at year $t$ and skill level skill, and $d^{s}$ is a dummy for whether sector $s$ is chosen, as function of the state variables. $\widetilde{\Omega}_{i a t}$ is the state space of individual $i$ of age $a$ at time $t$, excluding the human capital prices.

The economy is simulated by sequentially drawing the individual idiosyncratic shocks 
and computing the equilibrium human capital prices.

7. Estimate the auxiliary models with the data that is simulated in step 6. Let $\widehat{\delta}^{S}(\Theta)$ denote the estimates of these models stacked up.

8. Compute the Indirect Inference loss function:

$$
Q(\Theta)=\left(\widehat{\delta}-\widehat{\delta}^{S}(\Theta)\right)^{\prime} \Omega\left(\widehat{\delta}-\widehat{\delta}^{S}(\Theta)\right)
$$

$Q(\Theta)$ is a measure of the distance between $\widehat{\delta}$ and $\widehat{\delta}^{S}(\Theta) . \Omega$ is a positive definite weighting matrix.

9. Use an optimization routine to guess a new set of structural parameters $\Theta$ and go back to 5 until $Q$ is minimized.

The procedure described above is illustrated in Figure 4.

The Indirect Inference method is very similar to the Simulated Method of Moments. Suppose we had a single auxiliary model, $y=X \beta+\varepsilon$ and let the weighting matrix be $X^{\prime} X$. The Indirect Inference loss function becomes:

$$
\begin{aligned}
Q(\Theta) & =\left(\widehat{\beta}-\widehat{\beta}^{S}(\Theta)\right)^{\prime} X^{\prime} X\left(\widehat{\beta}-\widehat{\beta}^{S}(\Theta)\right) \\
& =\left(X \widehat{\beta}-X \widehat{\beta}^{S}(\Theta)\right)^{\prime}\left(X \widehat{\beta}-X \widehat{\beta}^{S}(\Theta)\right) \\
& =(\widehat{E}[y \mid X]-\widehat{E}[y(\Theta) \mid X])^{\prime}(\widehat{E}[y \mid X]-\widehat{E}[y(\Theta) \mid X])
\end{aligned}
$$

Where $\widehat{E}$ denotes the best linear predictor operator and $y(\Theta)$ is the data generated by the model under parameter $\Theta$.

In that case, Indirect Inference matches best linear predictors.

\subsection{Auxiliary Models and Identification}

In constructing the Indirect Inference estimator, the researcher must choose auxiliary models that describe statistical relationships the researcher thinks her model should be able to reproduce. These models should be relatively simple and quick to estimate and are usually misspecified. They should also provide a sufficiently rich description of the data in order to allow the model to be identified.

In this paper, the statistical relationships that I will consider important to be generated by the model are (1) how wages vary over time and how they are correlated with observables, such as gender, education, age and sector-specific experiences; (2) wage dispersion after controlling for observable workers' characteristics; (3) how sectoral choices vary over time and how they are correlated with observable characteristics; (4) how transition rates between 
sectors vary over time and how they correlate with observable characteristics.

The auxiliary models used in the computation of $Q$ are described below:

\begin{tabular}{c|c|c}
\hline \hline & \multicolumn{2}{|c}{ Coefficient } \\
\hline Auxiliary Model & Fit to Actual Data & Fit to Simulated Data \\
\hline $\begin{array}{c}\text { Log wage linear regressions for } \\
\text { each sector } k=1, \ldots, 4\end{array}$ & $\widehat{\beta}^{k}$ & $\left(\widehat{\beta}^{k}\right)^{S}(\Theta)$ \\
\hline $\begin{array}{c}\text { Linear probability models for sectoral } \\
\text { choices for each sector } k=0, \ldots, 4\end{array}$ & $\widehat{\gamma}^{k}$ & $\left(\widehat{\gamma}^{k}\right)^{S}(\Theta)$ \\
\hline $\begin{array}{c}\text { Linear probability models for } \\
\text { transition rates for every pair } \\
\text { of sectors } j, k=0, \ldots, 4\end{array}$ & $\widehat{\varphi}^{j k}$ & $\left(\widehat{\varphi}^{j k}\right)^{S}(\Theta)$ \\
\hline \hline
\end{tabular}

The same regressors are used for all auxiliary models: year dummies, gender and education dummies, age, age squared and sector-specific experience in each of the four sectors.

The log wage auxiliary models are misspecified due to the presence of self-selection based on unobservable components of wages. However, the model should be able to generate the same correlation pattern between wages and workers' characteristics than the ones found in the data. Due to the complexity of the model and its lack of analytical solution, it is not possible to make a purely constructive argument for identification. However, it is possible to give some intuition on why the structural parameters are identified.

First, consider the human capital production functions' parameters. Self-selection is fully taken into account and hence following Heckman (1979), the wage equation parameters should be identified by both an exclusion restriction and the functional form assumption on the idiosyncratic terms. ${ }^{13}$ The exclusion restriction here is the sector where a worker was active in the previous period: this variable matters for the current decision of the worker, but does not enter the wage equations, after we control for the sector-specific experience variables. The dispersion of the idiosyncratic shocks $\varepsilon$ is pinned down by sector-specific wage dispersion. That is, the volatility of the human capital shocks should map to the volatility of accepted offers.

The linear probability models for the decision of where to work (including the Residual Sector) help in the identification of the wage parameters, but are also crucial in identifying the parameters of the value of Residual Sector. Fixing the parameters of the wage equation, the "employment rates" of sectors $j=0, \ldots, 4$, conditioned on characteristics, identify the value of the Residual sector parameters.

\footnotetext{
${ }^{13}$ When the model has an exclusion restriction, the normal functional form assumption is not necessary to ensure identification.
} 
Finally, the linear probability models for transition rates help to pin down the parameters in the costs of mobility function, once the wage parameters (including the volatility of the skill shocks) are fixed. These models, especially the ones where $k=0$ or $j=0$, also help to identify the volatility of the idiosyncratic shocks that enter the value of the Residual Sector.

The Indirect Inference loss function $Q(\Theta)$ is computed as:

$$
Q(\Theta)=L_{1}+L_{2}+L_{3}+L_{4}
$$

Where

$$
\begin{aligned}
& L_{1}=\sum_{k=1}^{4}\left(\widehat{\beta}^{k}-\left(\widehat{\beta}^{k}\right)^{S}(\Theta)\right)^{\prime}{\widehat{V\left(\widehat{\beta}^{k}\right)}}^{-1}\left(\widehat{\beta}^{k}-\left(\widehat{\beta}^{k}\right)^{S}(\Theta)\right) \\
& L_{2}=\sum_{k=0}^{4}\left(\widehat{\gamma}^{k}-\left(\widehat{\gamma}^{k}\right)^{S}(\Theta)\right)^{\prime}{\widehat{V\left(\widehat{\gamma}^{k}\right)}}^{-1}\left(\widehat{\gamma}^{k}-\left(\widehat{\gamma}^{k}\right)^{S}(\Theta)\right) \\
& L_{3}=\sum_{j=0}^{4} \sum_{k=0}^{4}\left(\widehat{\varphi}^{j k}-\left(\widehat{\varphi}^{j k}\right)^{S}(\Theta)\right)^{\prime}{\widehat{V\left(\widehat{\varphi}^{j k}\right)}}^{-1}\left(\widehat{\varphi}^{j k}-\left(\widehat{\varphi}^{j k}\right)^{S}(\Theta)\right) \\
& L_{4}=\sum_{k=1}^{4}\left(\frac{\widehat{\sigma}^{2, k}-\left(\widehat{\sigma}^{2, k}\right)^{S}(\Theta)}{\left.s e \widehat{\sigma}^{2, k}\right)}\right)^{2}
\end{aligned}
$$

$\widehat{\sigma}^{2, k}$ is the variance of the residuals of sector $k$ 's log wage regression.

$\widehat{V\left(\widehat{\beta}^{k}\right)}, \widehat{V\left(\widehat{\gamma}^{k}\right)}$ and $\widehat{V\left(\widehat{\varphi}^{k}\right)}$ are the OLS variances under homoskedasticity and hence take the standard form $\widehat{\sigma}^{2}\left(X^{\prime} X\right)^{-1}$.

\section{Results}

\subsection{Parameter Estimates}

In order to make the estimation more tractable, I imposed the following structure on the switching costs:

$$
\begin{aligned}
& \varphi^{s s^{\prime}}=\varphi^{1 s^{\prime}} \text { if } s \neq 0 \\
& \varphi^{s s^{\prime}}=\varphi^{0 s^{\prime}} \text { if } s=0
\end{aligned}
$$

That is, switching costs do not depend on the sector of origin $s$, unless the worker is coming from the Residual Sector. The original idea was to fix $\varphi^{s s^{\prime}}=\varphi^{s^{\prime}}$ regardless of the sector of origin $s$. However, because movements in and out of the Residual Sector are very 
frequent, the model must assign a high variance to the idiosyncratic shock in the value of the Residual Sector. Consequently, in order to match the transition rates from the Residual Sector, the model must assign a higher cost of switching if a worker is coming from the Residual Sector.

The parameter estimates can be found in Tables 4, 5 and 6. Appendix B describes how standard errors were computed.

Table 4 shows the human capital production functions' estimated parameters. There are two types of human capital (unskilled and skilled) but they share the same parameters. The only difference between these human capital production functions is that among the unskilled workers the education dummy is $(E d u c=2)$ and among the skilled workers it is $(E d u c=4)$.

The sector-specific experience coefficients indicate that sector-specific experience accumulated in sector $i$ is usually transferable to sector $j \neq i$. That is, when workers switch sectors, not all experience is lost. However, sector-specific experience accumulated in sector $i$ is not fully transferable to sector $j$, which creates direct wage costs in switching sectors. Nevertheless, this result also shows that models that assume the complete loss of sector-specific experience when switching sectors overstate this barrier to mobility.

Experience accumulated in High-Tech Manufacturing $\left(\right.$ Exper $\left._{3}\right)$ is quite transferable to all the sectors. However, experience accumulated in Agriculture and Mining (Exper $\left.{ }_{1}\right)$ seems to be transferable only to Low-Tech Manufacturing. It can even hurt productivity in High-Tech Manufacturing, although this result might be due to an unobservable compositional effect that is not present in the model: there might be a permanent and unobservable component in the human capital production functions of workers who self-select into Agriculture/Mining that prevents them from moving to High-Tech Manufacturing. Experience accumulated in Low-Tech Manufacturing $\left(\right.$ Exper $\left._{2}\right)$ is only marginally useful in other sectors. Finally, experience accumulated in the Non-Tradeables $\left(\right.$ Exper $\left._{4}\right)$ sector appears to contribute to productivity only in Low-Tech Manufacturing.

It is interesting to note that on average, male, more educated and older workers all attach higher values to the Residual Sector. Hence, these observable characteristics, all else equal, lead to higher reservation wages. The standard deviation of idiosyncratic shocks for the value of the Residual Sector (in Table 5) is large, in the order of five times median annual wages. This high volatility is necessary for the model to be able to match frequent transitions in and out of the formal sector.

In order to interpret the magnitudes of the costs of mobility (whose parameters are shown in Table 6), for each worker $i$ in the data set, I express individual costs of mobility in terms of 
annual average wages, conditional on worker $i$ 's characteristics. ${ }^{14}$ Table 7 shows the median of costs of mobility, expressed as multiples of conditional annual average wages. For workers currently employed in the formal sector, median costs of mobility into Agriculture/Mining are equal to 0.68 times annual average wages, but costs of mobility into High-Tech Manufacturing are much higher and equal to 3.25 conditional annual average wages. Costs of mobility into Low-Tech Manufacturing and Non-Tradeables are in between and equal to 1.5 and 2.15 times conditional annual average wages respectively.

These numbers appear very high. However, given that workers choose sectors comparing the present value of each sector, a better way to express costs of mobility is in terms of the present value of staying in the current sector. In this metric, median costs of mobility toward Agriculture/Mining equal 3\% of the present value of staying in the current sector and the median costs of mobility toward High-Tech Manufacturing is equal $13 \%$.

In order to interpret these numbers, suppose that an economy has two sectors initially offering the same wages to workers with the same characteristics. If a shock increases wages in sector 2 by 13\%, and workers perceive this increase as permanent, then half of the workers in sector 1 would switch sectors (not considering equilibrium effects).

The costs of mobility from the Residual Sector are less interpretable. These costs are extremely high, since the model must assign a very high variance of the shocks in the value of the Residual Sector in order to explain the frequent movements in and out of the formal sector.

Table 8 shows regressions of costs of mobility in terms of conditional annual average wages on various workers' characteristics. We can see that individual costs of switching, in terms of annual average wages, is higher for less-educated workers, women and older workers. These are the least-mobile workers in the economy.

Finally, Figure 6 shows how dispersed these costs of mobility are, by plotting the nonparametric densities of these costs. These costs are dispersed only because they depend on workers' characteristics. There is considerable variability in workers' abilities to arbitrage wage differentials, and this is explained by their demographic characteristics.

It is worth noting, at this point, that the magnitude of costs of mobility is model dependent. Transition rates depend on wage differentials between sectors but also on the ratio between the variance of the idiosyncratic shocks and costs of mobility. High variance in the idiosyncratic shocks must be accompanied by high costs of mobility in order to match the

\footnotetext{
${ }^{14}$ The cost of mobility of worker $i$ in sector $s$ toward sector $s^{\prime}$, expressed in terms of conditional annual average wages, is given by: $c_{i}^{s^{\prime}}=\frac{\operatorname{Cost}^{s s^{\prime}}\left(X_{i}\right)}{\exp \left(\widehat{E}\left[\log (w) \mid X_{i}\right]\right)}$, where $\operatorname{Cost}^{s s^{\prime}}\left(X_{i}\right)$ is the cost individual $i$ with characteristics $X_{i}$ will incur if she switches from sector $s$ to sector $s^{\prime}$ and $\widehat{E}\left[\log (w) \mid X_{i}\right]$ is worker's $i$ best linear predictor for his log wage, unconditional on sector.
} 
transition rates in the data. If the model is extended in order to allow for permanent unobservable heterogeneity, for example, the variance of the idiosyncratic shocks will naturally decrease, leading to smaller costs of mobility. ${ }^{15}$ On the other hand, the dispersion on these mobility costs is a more general result, and that should be emphasized.

\subsection{Goodness of Fit}

I now discuss how well the model fits the features of the data used in the estimation.

In light of equation (22), I plot:

Figure $7-\widehat{E}\left[\log \left(w_{i t}^{s}\right) \mid X_{i t}\right]$ vs. $\widehat{E}\left[\log \left(w_{i t}^{s}(\widehat{\Theta})\right) \mid X_{i t}\right]$ for all workers in sector $s$ at time $t$.

Figure $8-\widehat{E}\left[d_{i t}^{s} \mid X_{i t}\right]$ vs. $\widehat{E}\left[\log \left(d_{i t}^{s}(\widehat{\Theta})\right) \mid X_{i t}\right]$ for all workers in the data set. $d_{i t}^{s}$ is a dummy for whether worker $i$ chose sector $s$ at time $t$.

Figure $9-\widehat{E}\left[d_{i t}^{s s^{\prime}} \mid X_{i t}\right]$ vs. $\widehat{E}\left[\log \left(d_{i t}^{s s^{\prime}}(\widehat{\Theta})\right) \mid X_{i t}\right]$ for all the workers in sector $s$ at time $t-1$. $d_{i t}^{s s^{\prime}}$ is a dummy for whether worker $i$ switched from sector $s$ to $s^{\prime}$ from $t-1$ to $t$.

$X_{i t}$ is a vector of characteristics for worker $i$ in period $t$ : year dummies, gender and education dummies, age, age squared and sector-specific experience in each of the four sectors. The distribution of $X$ is comes from the data. $\widehat{\Theta}$ is the vector of estimated parameters.

In other words, Figures 7, 8 and 9 plot the best linear predictors in the data versus the best linear predictors generated by the model at the estimated parameter value. Each point in each figure corresponds to an observation $X_{i t}$ in the data. A perfect model fit would lead to all points on top of the $45^{\circ}$ line. The model performs reasonably well in explaining the best linear predictors of log wages, sectoral choices and transition rates.

Tables 9, 10 and 11 compare unconditional wage, sectoral choice and transition rate moments in the data and those generated by the model. The model reproduces the unconditional moments remarkably well. Appendix $\mathrm{C}$ shows how well the model fits additional features of the data which were not imposed in the estimation.

\section{Counterfactual Experiments}

In this section, I use the model as a laboratory in order to analyze the dynamics of the labor market following a counterfactual trade liberalization episode. I focus on the following issues:

\footnotetext{
${ }^{15}$ This illustrates the importance of counterfactual experiments in understanding the dynamics of the labor market.
} 
1. Quantify the speed of adjustment with which the labor market readjusts as a response to trade liberalization.

2. Investigate the impact of assumptions regarding the mobility of physical capital on the transition path.

3. Quantify welfare losses for workers initially employed in the adversely affected sector, and determine how these losses correlate with demographic characteristics.

4. Quantify adjustment costs: how much of the present value of gains from trade liberalization is lost due to the slow labor market adjustment when compared to an economy that adjusts immediately and with no costs to the new steady state?

5. Attempt to quantify the relative importance of costs of mobility to sector-specific experience in explaining the slow adjustment.

6. Analyze the impact of different labor market policies on real value added, aggregate welfare, welfare losses of workers initially employed in the adversely affected sector and on the speed of adjustment.

The general procedure will be to:

1. Generate a stable economic environment. All the parameters of the model will be fixed over time, as will the stock of physical capital and the characteristics of the upcoming generations of workers. Simulate the model long enough so that the distorted-trade steady state is reached.

2. Shock the economy with a trade liberalization episode. The trade liberalization episode will consist of a once-and-for-all negative shock in the price of the High-Tech Manufacturing sector (the import-competing sector) of 30\%. This negative shock is interpreted as being induced by a decrease in the tariffs imposed in that sector. The prices of Agriculture/Mining and of Low-Tech Manufactures will be kept constant but the prices of Non-Tradeables will adjust endogenously. This is a standard small open economy assumption. The prices of tradeables are all determined in international markets and the domestic economy is assumed to be small enough to have no impact on these prices.

3. Analyze the outcome of interest.

The next sub-section goes over some additional features that must be incorporated to the model when carrying out and analyzing the simulations. These features were irrelevant in estimation. Appendix D provides the details of how I proceed with the simulations of the counterfactual experiments. In particular, it explains how the productivity terms and total stock of physical capital used in the simulations are determined. 


\subsection{Closing the Model For the Simulations}

\subsubsection{Capital Owners}

Capital owners were not mentioned in the model outline of Section 2. However, I need to detail their participation in the economy in order to endogenize the price of Non-Tradeables and to define welfare. In the experiments, the total stock of physical capital is fixed over time and hence no investment decisions are modeled.

Capitalists are passive: they receive payments for the rental of their capital and consume. They enjoy utility $U(\mathbf{C})=\left(\prod_{k=1}^{4} C_{k}^{\mu_{k}}\right)$ of consumption, with the same expenditure shares as workers. Their indirect utility at time $t$ is given by: $\frac{\text { Total Capital Income } t}{\prod_{k=1}^{4} p_{k t}^{\mu_{k}}}=\sum_{k=1}^{4} r_{t}^{K, k} K_{t}^{k}$. Where $r_{t}^{K, k}$ is the real rental price of capital in sector $k$.

\subsubsection{Market Clearing for Non-Tradeables}

In the simulations, the prices of Agriculture/Mining and of Low-Tech Manufacturing will be kept constant, but the price of Non-Tradeables will adjust endogenously. All Non-Tradeable output must be consumed domestically. Hence (in nominal terms):

$$
Y_{t}^{4}=p_{t}^{4} C_{t}^{4}
$$

Given the Cobb-Douglas utility functions, we have the following chain of equalities (in nominal terms):

$$
p_{t}^{4} C_{t}^{4}=\mu^{4}(\text { Wage Bill }+ \text { Capital Income })=\mu^{4}\left(\sum_{k=1}^{4} Y_{t}^{k}\left(\mathbf{p}_{t}\right)\right)=Y_{t}^{4}\left(\mathbf{p}_{t}\right)
$$

The last equality pins down $p_{t}^{4}$ as a function of $p_{t}^{1}, p_{t}^{2}, p_{t}^{3} \cdot \mu^{4}$ is the expenditure share on Non-Tradeables.

\subsubsection{Welfare}

When computing welfare we need to add up workers' utility (5) to the real capital income $\sum_{k=1}^{4} r_{t}^{K, k} K_{t}^{k}$. Welfare is hence given by real value added plus the utility of workers in the Residual Sector minus incurred costs of switching.

Real value added is an incomplete measure of welfare, since it does not take into account 
that workers have a disutility cost in switching sectors and that there are also workers in the Residual Sector, each enjoying utility $w_{i}^{0}$.

\subsubsection{Expenditure Shares}

Expenditure Shares are calibrated in order to match the average net exports $(\overline{N X})$ in the Brazilian National Accounts from 2002 to 2005.

$$
\mu_{s}=\frac{\bar{Y}^{s}-\overline{N X}^{s}}{\sum_{k=1}^{4}\left(\bar{Y}^{k}-\overline{N X}^{k}\right)} s=1, \ldots, 4
$$

The shares are presented in Table 12.

\subsection{Simulations: Perfect Physical Capital Mobility}

For the simulations presented in this sub-section, physical capital is assumed to be perfectly mobile (efficiently allocated) across sectors.

Figure 10 shows the main results of the simulation. All prices are normalized to 1 in the pre-shock, distorted-trade steady state.

The shock in the price of High-Tech Manufacturing occurs at year 1, when that price drops from 1 to 0.7. The prices of Agriculture/Mining and Low-Tech Manufacturing are set to 1 throughout (small open economy assumption). The price of Non-Tradeables is determined in equilibrium and gradually adjusts to its new steady state value.

Human capital prices in the adversely affected sector drop violently together with the shock. There are some dynamics on these prices, although most of the transition is accomplished in the first year.

On the other hand, the adjustment of the labor market is rather sluggish. $80 \%$ of the reallocation out of High-Tech Manufacturing is accomplished after 7 years and $95 \%$ of the reallocation is complete after 13 years. Although sluggish, there is a sizeable adjustment in the labor market. Employment in High-Tech Manufacturing drops to virtually zero in the new steady state. The price shock in this sector is big, causing both workers and capital to be reallocated elsewhere. This extreme result occurs because physical capital is perfectly mobile. The intuition behind this is that the price in High-Tech drops, driving wages in that sector down, making some workers leave the sector. With less human capital in the sector, marginal product of capital decrease, inducing capital to be allocated elsewhere. That decreases wages further, making additional workers leave, and so on and so forth. Additionally, the costs of

switching into the High-Tech sector are the highest. As long as the human capital prices 
in that sector were high, it was worthwhile for workers to incur the costs and switch there. However, with declining wages in that sector, many workers leave and fewer enter.

It is worth emphasizing that the long-run magnitude of the impact of the trade shock on the level of employment in High-Tech is not only driven by the size of the shock, but more importantly by the extreme assumption regarding capital mobility. A $10 \%$ adverse shock in the price of High-Tech Manufacturing would be enough to drive steady state employment in that sector from $4.3 \%$ to $1.3 \%$, yielding a price elasticity of about 7 .

The level of real value added and aggregate welfare are normalized to 1 before the shock. The long term gain in real value added is of $3.24 \%$, but the economy goes through a significant delay in reaching the new state. $80 \%$ of the transition is completed only after 8 years and $95 \%$ of the transition is completed only after 14 years. Long term welfare gains are of $1.63 \%$. The welfare gains are much smaller than the gains in real value added since, every year, a sizeable portion of the economy chooses the Residual Sector. The value of the Residual Sector is not affected by prices, and hence this dilutes the gains from liberalization.

Although not reported here, the skill premia (defined as $\frac{r_{t}^{1, s}}{r_{t}^{0, s}}$ ) across sectors slightly declines in the long run following the shock, which is the expected direction, since High-Tech Manufacturing is relatively intensive in skilled workers' human capital. However, the long run decrease in the skill premium is very marginal.

\subsection{Simulations: No Physical Capital Mobility}

Figure 11 shows the dynamics of the labor market following the price shock in High-Tech Manufacturing when physical capital is immobile. Capital cannot reallocate across sectors.

The perverse spiral that occurs when capital is perfectly mobile is absent here. There will always be the same amount of capital in High-Tech Manufacturing, so that an exodus of workers out of that sector can only push human capital prices up, slowing down the flow of workers out of that sector.

This is the phenomenon we observe in the human capital price figures. The drop in HighTech Manufacturing prices first drive real human capital prices down in that sector because workers are not perfectly mobile. However, the exodus of workers out of the adversely affected sector pushes human capital prices up. The long run real human capital prices are quite similar to the pre-shock levels.

Contrary to the case where capital is perfectly mobile, Figure 11 shows that the HighTech Manufacturing sector does not die out in the long run. Adjustment of the labor market is much faster, but the magnitude of adjustment is smaller than with perfect capital mobility. $80 \%$ of the reallocation out of High-Tech Manufacturing takes 3 to 4 years and $95 \%$ of the 
reallocation is completed after 5 to 6 years. When capital is immobile, the transition of value added after the shock is also reasonably fast. $80 \%$ of the transition is completed in the first year. The transition is fully completed after 5 years. Since capital cannot reallocate across sectors, the gains from the trade shock are rather modest. The long-term gain in real value added is of $1.22 \%$ and the long-term gain in aggregate welfare is of $0.63 \%$.

\subsection{Simulations: Imperfect Physical Capital Mobility}

In this section, physical capital is assumed to be imperfectly mobile for illustration purposes. There are many different ways to impose frictions on the mobility of physical capital. Moreover, since these frictions were not estimated, assuming numbers for the magnitude of these frictions is inevitably arbitrary. Consequently, this section should be viewed as an example of how imperfect physical capital mobility interacts with the labor market in generating slow transitional dynamics.

I assume that, at each year, 5\% at most of each sector's capital can change hands. Therefore, physical capital is perfectly mobile in the long run, but not in the short run.

Figure 12 shows the dynamics under this assumption.

In the short run, real human capital prices in High-Tech Manufacturing behave as in an economy with immobile capital, with an initial fall and subsequent recovery. But in the long run, as capital flees the adversely affected sector, the economy behaves as it would in an economy where capital is perfectly mobile.

The adjustment of the labor market is much slower. $80 \%$ of the reallocation of HighTech Manufacturing is completed only after 25 years. 95\% is completed after 55 years. The duration of the transition in real value added shows similar numbers. The slow mobility of capital interacts with the labor market amplifying the duration of the transition. Figure 13 compares the employment shares in High-Tech Manufacturing after the shock for the three different assumptions on capital mobility. The transition patterns are very different. As a result, rigorously modeling physical capital mobility together with workers' barriers to mobility is a very important direction for future research.

\subsection{Adjustment Costs}

Table 13 shows welfare losses for workers who were employed in High-Tech Manufacturing - the adversely affected sector - prior to the adverse price shock, that is at time $t=0$. These are losses in terms of the present value of welfare, which are computed over the actual transition path and are relative to the welfare path that would have resulted in the 
absence of the shock. Welfare losses are computed for different demographic groups and under different assumptions regarding the mobility of physical capital.

Under perfect capital mobility, the welfare losses for the group as a whole is $13.7 \%$. Older workers (45 to 59 years old in the year before the shock) lose less in terms of welfare than younger workers (25 to 39 years old in the year before the shock). Moreover, within age categories, unskilled workers are more adversely affected than skilled workers. Since older workers are less mobile than younger workers (they have higher costs of mobility), it should come as a surprise that the latter are more worse off. However, older workers also have a higher value of the Residual Sector, and as a result of the adverse shock, drop out of the formal labor market more frequently than younger workers and wait until they have a good formal-sector wage offer in order to come back (or for a bad shock in the Residual Sector). Dropping out of the formal labor market is less of an option for younger workers. Their value of the Residual Sector is lower and they need to keep accumulating sector-specific experience. Thus, they know they will have to come back to the formal labor market soon and high mobility costs will have to be incurred, making a move to the Residual Sector relatively less attractive.

Under immobile capital or imperfectly mobile capital, Figures 11 and 12 show that human capital prices in the adversely affected sector see an immediate drop as a response to the shock but they also go through a short-run recovery. That explains why workers employed in High-Tech Manufacturing right before the shock suffer smaller losses under these assumptions for physical capital than under perfect mobility.

I now compute adjustment costs as suggested in Davidson and Matusz (2010). Let $W_{D T}(\infty)$ be the steady state aggregate welfare before the shock (DT standing for distorted trade) and $W_{F T}(\infty)$ the steady state aggregate welfare after the shock ( $F T$ standing for free trade).

If the transition were immediate, then the present value of the gains would be:

$$
G=\frac{1}{1-\rho}\left(W_{F T}(\infty)-W_{D T}(\infty)\right)
$$

However, the transition is similar to the graph depicted in Figure 14 (see the bottom figures of Figures 10, 11 and 12). $W_{A}$ is aggregate welfare over the adjustment path at time t. Adjustment costs are defined by:

$$
A C=\frac{1}{1-\rho} W_{F T}(\infty)-\sum_{t=0}^{\infty} \rho^{t} W_{A}(t)
$$

The slower the adjustment - the further $W_{A}$ is shifted down and towards the right - the 
larger the adjustment costs.

Table 14.A shows that, under perfect capital mobility, adjustment costs eat up about $16 \%$ of the gains in aggregate welfare and $12 \%$ of the gains in real value added. Under imperfect capital mobility, these numbers are much larger: $32 \%$ of aggregate welfare and $27 \%$ of real value added.

Table 14.B shows adjustment costs under no capital mobility. The adjustment of real value added is quite fast ( $80 \%$ of the adjustment is completed in 1 year) and there is a slight overshooting with respect to the new steady state value. The adjustment costs in terms of both real value added and aggregate welfare turn out to be negative due to the short term overshooting. These measures of welfare peak in the years following the shock and decline slightly in the long run.

In conclusion, if capital is assumed to be immobile, adjustment costs are low and adjustment is fast. However, the long term gains from trade are half of those when capital can be reallocated. If capital can be reallocated (either perfect or imperfectly), adjustment costs become large. An understanding of how these costs might be reduced is important.

\subsection{Costs of Mobility Versus Sector-Specific Experience}

Table 4 shows that experience accumulated in High-Tech Manufacturing is, to a certain degree, transferable to all other sectors. Consequently, since the adversely sector is HighTech Manufacturing, one would not expect that sector-specific experience would be the most important barrier to mobility for the affected workers.

One possible way to further investigate the relative importance of costs of mobility versus sector-specific experience in explaining the slow adjustment of the labor market would be to completely shut down costs of switching. Subsequently, we would let the economy attain its new distorted trade steady state, shock the price of High-Tech Manufacturing and compare the speed of labor market reallocation as compared with the economy with costs of mobility.

This approach ignores the fact that the existence of wage differentials can itself be a barrier to mobility - for those workers in sectors paying higher premiums - and that an economy with smaller costs of mobility will have smaller wage differentials. Accounting for this fact, Figure 15 gradually reduces the costs of mobility and looks at how the speed with which workers leave High-Tech Manufacturing changes. Each line in the graph corresponds to costs of mobility equal to $\phi \times($ Actual Estimated Costs $)$. That is, all individual mobility costs are reduced by the same percentage given by $1-\phi$, where $\phi$ goes from 1.0 to 0.5 . The reason behind this procedure is that an economy with $\phi=1.0$ is more comparable to an economy with $\phi=0.9$ than to an economy with $\phi=0.0$, so the idea behind Figure 15 is to 
have a set of two by two comparable economies (although still not perfectly comparable). The figure shows that the smaller the mobility costs, the faster is reallocation.

When costs of mobility are reduced to half $(\phi=0.5), 80 \%$ of the reallocation is completed after 3 years. This is a major increase in the speed of adjustment as compared to when mobility costs are incurred in full $(\phi=1.0)$. However, since there is an ex-ante high wage premium in working in High-Tech Manufacturing, one must keep in mind that faster reallocation with $\phi=0.5$ is a result of both smaller costs of mobility and flatter wage differentials.

Although we cannot decompose the speed of adjustment in three components (mobility costs, sector-specific experience and opportunity costs due to wage differentials), the results in Figure 15 together with those in Table 4 strongly suggest that mobility costs are the main component in the slow adjustment of the labor market.

It is important to note that this is not a general statement. The above statement depends on the fact that the adverse shock affected a sector in which specific experience is transferable across sectors.

\subsection{Labor Market Policies}

I now use the framework developed in this paper in order to analyze the impact some advocated labor market policies have on the labor market. I focus on the impact of these policies on costs of adjustment as defined in equation (30), speed of adjustment and on the welfare of workers in the adversely affected sector (High-Tech Manufacturing). Perfect mobility of physical capital will be assumed throughout.

The first policy consists of a retraining program. The two other policies are two different types of moving subsidies, financed with lump sum transfers. In light of the competitive equilibrium nature of the model and the welfare theorems, the latter cannot be welfare improving, but may have attractive implications for compensation and/or speed of adjustment.

\subsubsection{Retraining Program}

A retraining program is simulated as follows. Eligible workers face three additional options: retrain to enter Agriculture/Mining, retrain to enter Low Tech Manufacturing or retrain to enter Non-Tradeables. Retraining lasts one year, workers are not productive while being retrained and get $w^{0}$, the individual value of the Residual Sector. However, after a year of retraining they enter the sector for which they retrained with 2 additional years of sectorspecific experience in the chosen sector. In other words, one year of retraining for a sector is worth two years of sector-specific experience in that sector, but workers must stay out of the formal labor market for a year. 
Workers have to incur a cost of switching into a retraining program. For example, if a worker decides for retraining in sector $s$, she incurs the cost of moving into $s$. However, after the year spent retraining, she will have access to the sector she retrained to with no cost. Eligible workers are those employed at High-Tech Manufacturing at year $t=0$, right before the adverse price shock. A worker loses eligibility if and only if she chooses to switch directly to one of the remaining sectors (without retraining) or once she takes up a retraining program for any sector. Eligible workers keep their eligibility if they switch to the Residual Sector.

The retraining program is implemented for 5 years, that is, eligible workers can take up the retraining program until $t=5$, and they are aware of that.

Since we cannot know the cost of the retraining program, I initially assume that it is costless. The maximum amount a government is going to be willing to pay for it is equal to the welfare gains it produces.

The upper panel of Figure 16 shows the impact of the retraining program on real value added. Compared to the "no policy" benchmark, the retraining program reduces real value added in the first 5 years (the duration of the program). However, real value added is higher after the program expires and until it converges to the "no policy" benchmark. When a worker chooses to be retrained, it is assumed that she does not produce. This explains the reduction of real value added with respect to the "no policy" benchmark during the period when the program is implemented, since many workers are being retrained, and hence are unproductive. However, in the first year after the program expires, all the retrained workers are productive and the economy has a larger human capital endowment than under the "no policy" benchmark. Consequently, real value added increases relatively to the "no policy" benchmark in the years following the end of the program.

On the other hand, Table 16 shows that the retraining program has virtually no impact on adjustment costs due to this relative decline in real value added in the short run and later recovery. This result ignores any cost of the retraining program. Therefore, upon introducing costs of retraining, adjustment costs with respect to real value added will be larger under a retraining program than under the "no policy" benchmark.

The lower panel of Figure 16 shows that the retraining program increases welfare at every single point in time. This implies that, if aggregate welfare is the main concern of the government, there is a range of costs for which the retraining program is welfare-improving. Adjustment costs are reduced from $16 \%$ to $8 \%$ under this program (Table 16). Consequently, if the re-training program costs up to $8 \%$ of the frictionless gains from liberalization, the program is worthwhile to implement. This does not contradict the welfare theorems, since in that case, transfers are used in order to build additional human capital, improving the 
economy's endowment.

Figure 17 analyzes the speed with which workers leave the High-Tech Manufacturing sector, following the shock. The vertical axis shows what percentage of the reallocation out of that sector is completed at each point in time. The retraining program is successful in attracting workers out of the declining sector more quickly.

Lastly, Table 15 shows the impact of the retraining program on the losses incurred by those workers who were employed in High-Tech Manufacturing right before the trade shock occurred. The program is successful in reducing the losses incurred by older workers, but less so in compensating younger workers. In the aggregate, trade-induced welfare losses for these workers are reduced from $13.7 \%$ under the "no policy" benchmark to $9.4 \%$ under the retraining program.

\subsubsection{Wage moving subsidy of $20 \%$}

Under this program, eligible workers receive a $20 \%$ increase in the accepted wage, if the formal sector chosen is not High-Tech Manufacturing. Eligible workers are those employed in High-Tech Manufacturing at year $t=0$, right before the adverse price shock. There is no subsidy for choosing the Residual Sector. Eligible workers lose eligibility to the subsidy only when the program expires. The program is financed through lump sum taxes. This program is also implemented for 5 years, and workers are aware of that.

Figure 16 shows that this moving subsidy of $20 \%$ is successful in increasing real value added at each point in time, relatively to the "no policy" benchmark. However, the increase is rather small. Table 16 shows that its impact on adjustment costs, when welfare is measured by real value added, is only marginal.

The impact of this program on aggregate welfare, shown in the lower panel of Figure 16, is also marginal, but negative nontheless. Figure 17 shows that the moving subsidy is able to accelerate the transition out of the High-Tech Manufacturing, although the retraining program is slightly more successful in doing so.

Finally, Table 15 shows the impact of the moving subsidy program on the losses incurred by those workers who were employed in High-Tech Manufacturing right before the trade shock occurred. The program is somewhat successful in reducing the losses of skilled workers. However, the program does not adequately compensate the unskilled workers. The overall welfare compensation is timid when compared to the compensation provided by the retraining program. 


\subsubsection{Wage moving subsidy which covers switching costs}

Under this program, eligible workers are compensated with the mobility cost they incur when switching sectors if the destination sector is not the High-Tech Manufacturing sector. Eligible workers are those employed in High-Tech Manufacturing at year $t=0$, right before the adverse price shock. Eligibility is lost after a worker is compensated once or after the program expires. If an eligible worker switches to the Residual Sector, she does not lose eligibility. Because workers are compensated with the mobility costs they incur when switching, this policy is labeled "Zero Costs". The program is financed through lump-sum taxes. As the other two programs, the "Zero Costs" subsidy program is implemented for 5 years.

The upper panel of Figure 16 shows the impact of the "Zero Costs" program on real value added. Among the three policies analyzed in this paper, it is the one with the unambiguously worst impact on real value added. It gives incentives for eligible workers with good draws in the value of the Residual Sector to drop out of the labor market, retaining eligibility to later move to the formal sector without incurring switching costs. This reduces production during the implementation of the program. Table 16 shows that adjustment costs as measured by real value added increase to $17 \%$ with this policy.

The lower panel of Figure 16 shows the impact of this program on aggregate welfare. Apart from the first year of the program, aggregate welfare is substantially reduced by this intervention. As mentioned earlier, this policy gives incentives for workers to drop out of the formal labor market during the implementation of the program and eventually use the subsidy in order to re-access the formal labor market, incurring large switching costs, which

must be incurred by the economy. Aggregate welfare sees its lowest level at $t=5$, the last year of the program implementation. At this point, a mass of eligible workers initially located at the Residual Sector return to the formal labor market, incurring large mobility costs. Table 16 shows that adjustment costs, when measured with respect to aggregate welfare, jump from $16 \%$ to $22 \%$.

The decline in welfare under this policy is not surprising, in light of the welfare theorems. There is only room for this policy to better compensate the losers and/or to speed up adjustment. Indeed, Table 15 shows that this is the policy that best compensates those employed in High Tech Manufacturing right before the shock. Instead of suffering 13.7\% welfare losses under the "no policy" benchmark, under the "Zero Costs" policy, these workers suffer aggregate losses of only 3.7\%. Older workers especially benefit, and actually see gains.

Lastly, Figure 17 shows that the "Zero Costs" induces faster transition out of High-Tech Manufacturing. However, there is a larger fraction of workers moving to the Residual Sector first (later they will be able to have access to the formal labor market without incurring 
costs).

\subsubsection{Conclusion}

None of the three simulated policies are able to reduce adjustment costs, when these are measured with respect to real value added. However, the only policy that has the ability to increase aggregate welfare and hence reduce welfare adjustment costs (when these are measured in terms of aggregate welfare) is the retraining program. This is intuitive given the competitive equilibrium nature of the model, the welfare theorems and the fact that the other two policies are purely redistribution programs.

Nevertheless, the policy that best compensates the losers is the "Zero Costs" program. However, this comes at the expense of substantially larger adjustment costs, both in terms of real value added and in terms of aggregate welfare. That said, the retraining program also has a good compensation effect.

\subsection{Discussion}

A striking feature of the experiments conducted in this section is that although labor adjustment is slow, there is a large labor market response after the adverse price shock in the High-Tech Manufacturing sector. The speed and magnitude of the adjustment depends on the exact assumptions regarding the mobility of physical capital, but even under the extreme assumption of no capital mobility, the elasticity of employment in High-Tech Manufacturing with respect to its price is reasonably high.

One might think that the adverse price shock that was simulated was too large, and that this accounts for the large movements in the labor market. For this reason, Table 17 shows the long-run employment and wage elasticities in High-Tech Manufacturing following a 10\% adverse shock, in addition to the $30 \%$ adverse shock in its price. The elasticities are reported under both perfect capital mobility and under no capital mobility (fixed capital).

Under perfect capital mobility, a $10 \%$ adverse shock in the price of the High-Tech Manufacturing sector produces a long-run reduction of $70 \%$ in employment in that sector, yielding a price elasticity of 7 . The elasticity of wages with respect to prices is approximately 1.3, which is stable across skill groups and does not depend on the size of the shock. Finally, under the perfect capital mobility assumption, labor market responses are large, irrespective of the magnitude of the shock.

Under fixed capital, the elasticities are stable and do not depend much on the magnitude of the shock. The employment price elasticity is in the region of 1.3 and the wage elasticity varies between 0.12 and 0.17 , according to the skill group and size of the shock. These 
numbers, although smaller than the ones under perfect capital mobility, still show a large response of the labor market with respect to a trade liberalization episode. Additionally, these numbers are remarkably in line with the long-run elasticities obtained by Revenga (1992) using data from the US. She finds that her long period ( 5 years) price elasticities for employment and wage are given by 1.74 and 0.40 , respectively.

Goldberg and Pavcnik (2007) survey empirical studies on inter-sectoral reallocation following trade reform in developing countries and conclude that the available evidence points towards very little inter-sectoral reallocation. The lack of inter-sectoral reallocation in developing countries may be reconciled with the results obtained within the framework presented in this paper (and with the results in Revenga (1992)) with small pass-through from tariffs to domestic prices (e.g., with imperfect competition in product markets), faster productivity growth in the adversely affected sectors, high share of sector-specific and non-transferable physical capital, many forms of government subsidies towards the affected sectors, or a combination of all of these.

\section{Concluding Remarks, Extensions and Future Work}

This paper studies the short-to medium-run response of the labor market to trade-induced sectoral price changes. Within the framework presented, the paper assesses the distributional and welfare implications of the slow labor market adjustment. The framework also allows for the analysis of the performance of different labor market policies with the aim of reducing adjustment costs, compensating losers and/or speeding up adjustment.

First, I estimated a structural dynamic equilibrium model of the Brazilian labor market based on the framework of Lee (2005) and Lee and Wolpin (2006). The model features a multi-sector economy with overlapping generations, heterogeneous workers in several dimensions who have comparative advantage across sectors, endogenous accumulation of sectorspecific experience and costly switching of sectors.

The model's estimates point toward large workers' costs of switching sectors. Nevertheless, the distribution of these costs has a high dispersion within the population. The dispersion of mobility costs is only due to workers' observable characteristics such as gender, education and age. Older and less-educated workers face substantially higher costs of switching sectors. Moreover, in line with previous research by Neal (1995), this paper finds that sector-specific experience is imperfectly transferable across sectors, leading to additional barriers to mobility.

Second, the estimated model was used as a laboratory for counterfactual experiments. The findings indicate that: (1) there is a large response of the labor market following trade 
liberalization but the transition may last several years; (2) the duration and magnitude of the transition are very sensitive to assumptions regarding the mobility of physical capital; (3) workers employed in High-Tech Manufacturing right before the shock face substantial losses in welfare, especially the unskilled and the young; (4) adjustment costs - defined as the fraction of the potential gains from trade that are lost due to the slow and costly adjustment - are significant; (5) costs of mobility are more important than sector-specific experience in explaining the slow adjustment of the labor market, at least when the shock affects the High-Tech Manufacturing sector; (6) retraining workers initially employed in the adversely affected sector reduces welfare losses incurred by these workers and may increase aggregate welfare; and (7) a moving subsidy that covers switching costs is more promising in compensating workers initially employed in the affected sector, although at the expense of much higher adjustment costs.

The analyses conducted in this paper highlight the importance of modeling physical capital mobility together with labor mobility. The magnitudes of the size and speed of adjustment of the labor market depend crucially on assumptions regarding physical capital mobility. Estimating a model with imperfect mobility of both capital and labor is an important avenue for future work.

The current framework does not incorporate permanent unobserved heterogeneity in wages. This may be an important ingredient if comparative advantage across sectors has a permanent unobservable component. The standard way to model this permanent unobservable heterogeneity in the structural Labor Economics literature is to assume the economy has $H$ types of individuals with different patterns of comparative advantage across sectors, but these are unobservable to the econometrician. The introduction of these permanent unobservable components introduces an initial conditions problem: the initial conditions are endogenous and depend on the type of the individual. In other words, the initial conditions on the sector-specific experience variables carry important information on the type of each individual, and this must be taken into account in the estimation procedure. Following Wooldridge (2005), we could model the distribution of types conditioned on the initial conditions. The difficulty associated with this route is that it introduces a number of additional parameters to the model, the interpretation of which is not trivial. The optimization process becomes much more cumbersome and computational time considerably grows. I am currently estimating such a model. 


\section{References}

1. Amiti, M. and Davis, D. (2008) "Firms, Trade, and Wages: Theory and Evidence," NBER Working Paper 14106.

2. Artuç, E.; Chaudhuri, S. and McLaren, J. (2010) "Trade Shocks and Labor Adjustment: A Structural Empirical Approach," American Economic Review, 100(3), pp. $1008-45$.

3. Artuç, E. (2009) "Intergenerational Effects of Trade Liberalization," Working Paper.

4. Cosar, K. (2010) "Adjusting to Trade Liberalization: Reallocation and Labor Market Policies," Working Paper.

5. Cosar, K.; Guner, N. and Tybout, J. (2010) "Firm Dynamics, Job Turnover, and Wage Distributions in an Open Economy," Working Paper.

6. Cuñat, A. and Melitz, M. (2009) "Volatility, Labor Market Flexibility and Comparative Advantage," Journal of the European Economics Association, forthcoming.

7. Davidson, C.; Martin, L. and Matusz, S. (1999) "Trade and search generated unemployment," Journal of International Economics, 48, pp. 271-299.

8. Davidson, C. and Matusz, S. (2006) "Trade Liberalization and Compensation," International Economic Review, Vol. 47, No. 3, pp. 723-747.

9. Davidson, C. and Matusz, S. (2010), "Modeling, Measuring, and Compensating the Adjustment Costs Associated with Trade Reforms," in Porto, G. and Hoekman, B. (eds.), Trade Adjustment Costs in Developing Countries: Impacts, Determinants and Policy Responses, CEPR and World Bank.

10. Frías, J.; Kaplan, D. and Verhoogen, E. (2009) "Exports and Wage Premia: Evidence from Mexican Employer-Employee Data," Working Paper.

11. Goldberg, P. and Pavcnik, N. (2007) "Distributional Effects of Globalization in Developing Countries," Journal of Economic Literature, Vol. XLV, pp. 39-82.

12. Gollin, D. (2002) "Getting Income Shares Right," Journal of Political Economy, 110(2), pp. $458-474$.

13. Gouriéroux, C. and Monfort, A. (1996) "Simulation-Based Econometric Methods," Oxford University Press. 
14. Griliches, Z. (1977): "Estimating the Returns to Schooling: Some Econometric Problems," Econometrica, 45, pp. 1-22.

15. Heckman, J. (1979) "Sample Selection Bias as a Specification Error," Econometrica, Vol. 47, No. 1, pp. 153-161.

16. Heckman, J. and Honoré, B. (1990) "The Empirical Content of the Roy Model," Econometrica, Vol. 58, No. 5., pp. 1121-1149

17. Heckman, J. and Sedlacek, G. (1985) "Heterogeneity, Aggregation, and Market Wage Functions: An Empirical Model of Self-Selection in the Labor Market," Journal of Political Economy, Vol. 93, No. 6, (Dec., 1985), pp. 1077-1125.

18. Heckman, J. and Sedlacek, G. (1990) "Self-Selection and the Distribution of Hourly Wages," Journal of Labor Economics, Vol. 8, No. 1, Part 2: Essays in Honor of Albert Rees.

19. Helpman, E. and Itskhoki, O. (2009) "Labor Market Rigidities, Trade and Unemployment," Review of Economic Studies, 77 (3), pp.1100-1137.

20. Helpman, E.; Itskhoki, O. and Redding, S. (2010) "Inequality and Unemployment in a Global Economy," Econometrica, 78 (4), pp.1239-1283.

21. Kambourov, G. (2009) "Labor Market Regulations and the Sectoral Reallocation of Workers: The Case of Trade Reforms," Review of Economic Studies, 76(4), pp. 13211358.

22. Keane, M. and Wolpin, K. (1994) "The Solution and Estimation of Discrete Choice Dynamic Programming Models by Simulation and Interpolation: Monte Carlo Evidence," Review of Economics and Statistics, Vol. 76, No. 4, pp. 648-672.

23. Krusell, P. and Smith, A. (1998) "Income and Wealth Heterogeneity in the Macroeconomy," Journal of Political Economy, Vol. 106, No. 5, pp. 867-896.

24. Kume, H.; Piani, G. and Souza, C. (2000) "A política brasileira de importação no período 1987-1998: descrição e avaliação," In Corseuil, C. and Kume, H., Eds. Abertura Comercial Brasileira nos Anos 1990. Rio de Janeiro: IPEA; Brasília: MTE, 2003.

25. Lee, D. (2005) "An Estimable Dynamic General Equilibrium Model of Work, Schooling and Occupational Choice," International Economic Review, Vol. 46, No. 1, pp.1-34. 
26. Lee, D. and Wolpin, K. (2006) "Inter-sectoral Labor Mobility and the Growth of the Service Sector," Econometrica, Vol. 74, No. 1, pp.1-46.

27. Menezes-Filho, N. and Muendler, M. (2007) "Labor reallocation in response to trade reform," Working Paper.

28. Morandi, L. (2004) "Estoque e Produtividade de Capital Fixo - Brasil, 1940-2004," Textos para Discussão, UFF/Economia.

29. Neal, D. (1995) "Industry-Specific Human Capital: Evidence from Displaced Workers," Journal of Labor Economics, Vol. 13, No. 4, pp. 653-677.

30. Neary, P. (1978) "Short-run capital specificity and the pure theory of international trade," Economic Journal, 88, pp.488-510.

31. OECD Science Technology and Industry Scoreboard (2001) "Towards a Knowledge Based Economy".

32. Ohnsorge, F. and Trefler, D. (2007) "Sorting It Out: International Trade with Heterogeneous Workers," Journal of Political Economy, vol. 115(5), pp. 868-892.

33. Revenga, A. (1992) "Exporting Jobs?: The Impact of Import Competition on Employment and Wages in U.S. Manufacturing," The Quarterly Journal of Economics, Vol. 107, No. 1, pp. 255-284.

34. Roy, A. (1951) "Some Thoughts on the Distribution of Earnings," Oxford Economic Papers, 3, pp. 135-146.

35. Verhoogen, E. (2008) "Trade, Quality Upgrading and Wage Inequality in the Mexican Manufacturing Sector," Quarterly Journal of Economics, vol. 123, no. 2, pp. 489-530.

36. Willis, R. (1986) "Wage Determinants: A Survey and Reinterpretation of Human Capital Earnings Functions," in Handbook of Labor Economics, Vol. 1, ed. by O. Ashenfelter and R. Layard. Amsterdam: North-Holland, pp. 525-602.

37. Wooldridge, J. (2005) "Simple Solutions To The Initial Conditions Problem in Dynamic, Nonlinear Panel Data Models With Unobserved Heterogeneity," Journal of Applied Econometrics, 20, pp.39-54. 


\section{Tables}

Table 1: Correspondence Between 2-digit NAICS Industries and The Four Aggregate Sectors

\begin{tabular}{|c|c|}
\hline Agriculture/Mining & $\begin{array}{l}\text { Agriculture; Forestry; Fishing; Mineral Coal Extraction; Oil Ex- } \\
\text { traction; Metallic; Minerals Extraction; Non-Metallic Minerals } \\
\text { Extraction }\end{array}$ \\
\hline Low-Tech Manufacturing & $\begin{array}{l}\text { Food and Beverage; Tobacco Products; Textiles; Apparel; Leather } \\
\text { Products and Footwear; Wood Products; Paper; Cellulose; Paper } \\
\text { Products; Editing and Printing; Rubber and Plastic Products; } \\
\text { Non-Metallic Mineral Products; Basic Metals; Fabricated Metal } \\
\text { Products (except machinery and equipment); Furniture; Recy- } \\
\text { cling }\end{array}$ \\
\hline High-Tech Manufacturing & $\begin{array}{l}\text { Alcohol Production; Nuclear Fuels; Oil Refining; Coke; Chemi- } \\
\text { cal Products; Machinery and Equipment; Office, Accounting and } \\
\text { Computing Machinery; Electrical Machinery and Apparatus; Ra- } \\
\text { dio, Television and Communications Equipment; Medical, Preci- } \\
\text { sion and Optical Instruments; Motor Vehicles, Trailers and Semi- } \\
\text { Trailers; Other Transportation Equipment }\end{array}$ \\
\hline Non-Tradeables & $\begin{array}{l}\text { All other industries, including Utilities, Trade, Transportation, } \\
\text { Construction, Government, Services }\end{array}$ \\
\hline
\end{tabular}

Table 2: Median Hourly Wages in $2005 \mathrm{R} \$$ (1995 to 2005)

\begin{tabular}{ll}
\hline Overall & 3.94 \\
Agriculture/Mining & 2.24 \\
Low-Tech & 3.38 \\
High-Tech & 7.13 \\
Non-Tradeables & 4.13 \\
\hline
\end{tabular}


Table 3: Average Transition Rates (in \%) 1995 to 2005

\begin{tabular}{lccccc}
\hline & Residual & Agriculture/Mining & Low-Tech & High-Tech & Non-Tradeables \\
\hline Residual & 79.50 & 1.69 & 2.79 & 0.59 & 15.43 \\
Agriculture/Mining & 17.33 & 75.98 & 2.26 & 0.54 & 3.89 \\
Low-Tech & 13.91 & 0.80 & 79.35 & 0.78 & 5.16 \\
High-Tech & 10.48 & 0.60 & 2.25 & 81.26 & 5.40 \\
Non-Tradeables & 12.25 & 0.26 & 0.88 & 0.31 & 86.31 \\
\hline
\end{tabular}

Table 4: Human Capital Production Functions: Parameter Estimates

\begin{tabular}{|c|c|c|c|c|}
\hline & Agr/Mining & LT Manufacturing & HT Manufacturing & Non-Tradeables \\
\hline \multirow[t]{2}{*}{ Female } & -0.3407 & -0.2435 & -0.4188 & -0.2352 \\
\hline & $(0.0079)$ & $(0.0040)$ & $(0.0103)$ & $(0.0026)$ \\
\hline \multirow[t]{2}{*}{$I(E d u c=2)$} & 0.0226 & 0.2741 & 0.1793 & 0.2942 \\
\hline & $(0.0079)$ & $(0.0059)$ & $(0.0072)$ & $(0.0035)$ \\
\hline \multirow[t]{2}{*}{$I(E d u c=4)$} & 0.9679 & 0.8057 & 0.7929 & 0.8697 \\
\hline & $(0.0117)$ & $(0.0049)$ & $(0.0067)$ & $(0.0037)$ \\
\hline \multirow[t]{2}{*}{$(a g e-25)$} & 0.0341 & 0.0359 & 0.0414 & 0.0249 \\
\hline & $(0.0009)$ & $(0.0007)$ & $(0.0012)$ & $(0.0005)$ \\
\hline \multirow[t]{2}{*}{$(a g e-25)^{2}$} & -0.0013 & -0.0010 & -0.0014 & -0.0005 \\
\hline & $(0.00003)$ & $(0.00002)$ & $(0.00004)$ & $(0.00001)$ \\
\hline \multirow[t]{2}{*}{ Exper $_{1}$} & 0.1501 & 0.0920 & -0.1141 & 0.0261 \\
\hline & $(0.0013)$ & $(0.0020)$ & $(0.0108)$ & $(0.0028)$ \\
\hline \multirow[t]{2}{*}{ Exper $_{2}$} & 0.0210 & 0.1176 & 0.0101 & 0.0357 \\
\hline & $(0.0024)$ & $(0.0008)$ & $(0.0025)$ & $(0.0011)$ \\
\hline \multirow[t]{2}{*}{ Exper $_{3}$} & 0.0766 & 0.0876 & 0.1067 & 0.0642 \\
\hline & $(0.0022)$ & $(0.0018)$ & $(0.0018)$ & $(0.0015)$ \\
\hline \multirow[t]{2}{*}{ Exper $_{4}$} & 0.0292 & 0.0624 & 0.0029 & 0.1041 \\
\hline & $(0.0019)$ & $(0.0011)$ & $(0.0020)$ & $(0.0004)$ \\
\hline \multirow[t]{2}{*}{ SD of Shock } & 0.5510 & 0.5451 & 0.5472 & 0.7013 \\
\hline & $(0.0086)$ & $(0.0061)$ & $(0.0092)$ & $(0.0032)$ \\
\hline
\end{tabular}

Standard errors in parenthesis 
Table 5: Value of the Residual Sector: Parameter Estimates

\begin{tabular}{lc}
\hline Intercept & 0.9523 \\
& $(0.0132)$ \\
Female & -0.3243 \\
& $(0.0061)$ \\
$I(E d u c=2)$ & 0.3003 \\
& $(0.0116)$ \\
$I(E d u c=3)$ & 0.5723 \\
& $(0.0107)$ \\
$I(E d u c=4)$ & 1.7722 \\
& $(0.0107)$ \\
$($ age -25$)$ & 0.0140 \\
& $(0.0009)$ \\
$(\text { age }-25)^{2}$ & -0.0001 \\
& $(0.00003)$ \\
SD of Shock & 20.6143 \\
& $(0.1483)$ \\
\hline
\end{tabular}

Standard errors in parenthesis 
Table 6: Costs of Mobility: Parameter Estimates

\begin{tabular}{lc}
\hline Agr/Mining From Residual & 3.1940 \\
LT Manuf From Residual & $(0.0036)$ \\
& 3.2131 \\
HT Manuf From Residual & $(0.0048)$ \\
& 3.4233 \\
Non-Tradeables From Residual & $(0.0047)$ \\
& 3.1894 \\
Agr $/$ Mining From Formal & $0.0050)$ \\
& 0.7641 \\
LT Manuf From Formal & $(0.0454)$ \\
& 1.5450 \\
HT Manuf From Formal & $(0.0221)$ \\
& 2.2859 \\
Non-Tradeables From Formal & $(0.0252)$ \\
& 1.7795 \\
Female & $(0.0178)$ \\
& 0.0564 \\
I(Educ $=2)$ & $(0.0052)$ \\
I(Educ $=3)$ & 0.0733 \\
I(Educ $=4)$ & $(0.0060)$ \\
(age -25$)$ & 0.1976 \\
(age -25$)^{2}$ & $(0.0065)$ \\
& 0.5108 \\
& $(0.0086)$ \\
& 0.0278 \\
& $(0.0009)$ \\
& -0.0005 \\
& $(0.00003)$ \\
\hline
\end{tabular}

Standard errors in parenthesis 
Table 7: Median Costs of Mobility

\begin{tabular}{lcccc}
\hline & \multicolumn{2}{c}{$\begin{array}{c}\text { In Terms of Conditional } \\
\text { Average Annual Wages }\end{array}$} & \multicolumn{2}{c}{$\begin{array}{c}\text { In Terms of the Value of } \\
\text { Staying in the Current Sector }\end{array}$} \\
\hline To: & from Formal Sector & from Residual sector & from Formal Sector & from Residual Sector \\
\hline Agr/Mining & 0.68 & 11.41 & 0.03 & 0.41 \\
LT Manuf & 1.50 & 11.63 & 0.06 & 0.42 \\
HT Manuf & 3.25 & 14.35 & 0.13 & 0.51 \\
Non-Tradeables & 2.15 & 11.35 & 0.08 & 0.41 \\
\hline
\end{tabular}

Table 8: Correlates of Mobility Costs When Expressed in Terms of Annual Average Wages

\begin{tabular}{lcccc}
\hline & $\begin{array}{c}\text { Log Cost into } \\
\text { Agr } / \text { Min }\end{array}$ & $\begin{array}{c}\text { Log Cost into } \\
\text { LT Manuf }\end{array}$ & $\begin{array}{c}\text { Log Cost into } \\
\text { HT Manuf }\end{array}$ & $\begin{array}{c}\text { Log Cost into } \\
\text { Non-Tradeables }\end{array}$ \\
\hline \hline Female & 0.42712 & 0.41565 & 0.40451 & 0.44535 \\
& $(0.001)$ & $(0.001)$ & $(0.001)$ & $(0.003)$ \\
$I($ Educ $=2)$ & -0.16656 & -0.20033 & -0.19162 & -0.25618 \\
& $(0.001)$ & $(0.002)$ & $(0.001)$ & $(0.003)$ \\
$I($ Educ $=3)$ & -0.49028 & -0.52698 & -0.51788 & -0.61914 \\
& $(0.002)$ & $(0.002)$ & $(0.002)$ & $(0.004)$ \\
$I($ Educ $=4)$ & -1.05216 & -1.08600 & -1.07986 & -1.22926 \\
& $(0.002)$ & $(0.002)$ & $(0.002)$ & $(0.005)$ \\
$($ Age -25$)$ & -0.01894 & -0.01948 & -0.01724 & -0.01929 \\
& $(0.000)$ & $(0.000)$ & $(0.000)$ & $0.000)$ \\
$(\text { Age }-25)^{2}$ & 0.00046 & 0.00047 & 0.00041 & $(0.000)$ \\
& $(0.000)$ & $(0.000)$ & $(0.000)$ & 1.01645 \\
Constant & -0.06647 & 0.75952 & 1.50190 & $(0.004)$ \\
& $(0.002)$ & $(0.002)$ & $(0.002)$ & 50661 \\
\hline Observations & 202234 & 184633 & 204193 & 0.641 \\
\hline$R^{2}$ & 0.715 & 0.710 & 0.734 & \\
\hline
\end{tabular}

Standard errors in parenthesis

Note: Regressions estimated using a random sample of 50,000 individuals over 1995 to 2005. 
Table 9: Wages 1995-2005: Data vs. Model

\begin{tabular}{lcc}
\hline \multicolumn{3}{c}{ A. Average Hourly Wage (2005 } \\
Rector $\$$ ) $\mathbf{1 9 9 5 - 2 0 0 5}$ \\
Data & Model \\
\hline Agriculture/Mining & 3.93 & 3.89 \\
LT Manuf & 5.76 & 5.72 \\
HT Manuf & 11.64 & 11.91 \\
Non-Tradeables & 8.18 & 8.16 \\
\hline B. Average Log Hourly Wage (2005 $\mathbf{R} \$) \mathbf{1 9 9 5 - 2 0 0 5}$ \\
Sector & Data & Model \\
\hline Agriculture/Mining & 0.96 & 1.00 \\
LT Manuf & 1.37 & 1.42 \\
HT Manuf & 2.03 & 2.16 \\
Non-Tradeables & 1.58 & 1.61 \\
\hline
\end{tabular}

Table 10: Sectoral Choices (\%) 1995-2005: Data vs. Model

\begin{tabular}{lcc}
\hline & Data & Model \\
\hline Residual & 39.09 & 40.62 \\
Agriculture/Mining & 3.28 & 3.23 \\
LT Manuf & 8.43 & 8.30 \\
HT Manuf & 2.71 & 2.58 \\
Non-Tradeables & 46.48 & 45.27 \\
\hline
\end{tabular}


Table 11: Transition Rates (\%) 1995-2005: Data vs. Model

\begin{tabular}{lccccc}
\hline & \multicolumn{5}{c}{ A. Data } \\
& Residual & Agr/Min & LT Manuf & HT Manuf & Non-Tradeables \\
\hline Residual & 79.50 & 1.69 & 2.79 & 0.59 & 15.43 \\
Agriculture/Mining & 17.33 & 75.98 & 2.26 & 0.54 & 3.89 \\
LT Manuf & 13.91 & 0.80 & 79.35 & 0.78 & 5.16 \\
HT Manuf & 10.48 & 0.60 & 2.25 & 81.26 & 5.40 \\
Non-Tradeables & 12.25 & 0.26 & 0.88 & 0.31 & 86.31 \\
\hline \multicolumn{5}{c}{ B. Model } \\
& Residual & Agr/Min & LT Manuf & HT Manuf & Non-Tradeables \\
\hline Residual & 79.65 & 1.54 & 2.89 & 0.40 & 15.53 \\
Agriculture/Mining & 18.19 & 77.63 & 1.65 & 0.19 & 2.34 \\
LT Manuf & 16.28 & 0.50 & 79.88 & 0.33 & 3.01 \\
HT Manuf & 9.54 & 0.32 & 1.00 & 85.54 & 3.61 \\
Non-Tradeables & 13.58 & 0.21 & 0.54 & 0.23 & 85.44 \\
\hline
\end{tabular}

Table 12: Expenditure Shares

\begin{tabular}{ll}
\hline Agriculture/Mining & 0.09 \\
LT Manuf & 0.06 \\
HT Manuf & 0.09 \\
Non-Tradeables & 0.76 \\
\hline
\end{tabular}

Table 13: Welfare Changes (in \%) of Workers Who Were Employed in HT Manufacturing The Year Before The Shock

\begin{tabular}{lccc}
\hline & Perfect Capital Mobility & No Capital Mobility & Imperfect Capital Mobility \\
\hline Overall & -13.7 & -5.3 & -8.0 \\
\hline Old / Unskilled & \multicolumn{3}{c}{ By Demographics } \\
Old / Skilled & -12.3 & -3.4 & -5.7 \\
Young / Unskilled & -9.4 & -4.4 & -5.7 \\
Young / Skilled & -15.6 & -4.9 & -8.2 \\
\hline
\end{tabular}


Table 14: Adjustment Costs

\begin{tabular}{lccc}
\hline \multicolumn{4}{c}{ A. Adjustment Costs with Perfect and Imperfect Capital Mobility } \\
& $\begin{array}{c}\text { Long Term } \\
\text { Gain (\%) }\end{array}$ & $\begin{array}{c}\text { Adj. Cost w/ Perfect } \\
\text { Capital Mobility (\%) }\end{array}$ & $\begin{array}{c}\text { Adj. Cost w/ Imperfect } \\
\text { Capital Mobility (\%) }\end{array}$ \\
\hline Real Value Added & 3.24 & 11.77 & 27.29 \\
Welfare & 1.63 & 15.78 & 31.94 \\
\hline \multicolumn{4}{c}{ B. Adjustment Costs with No Capital Mobility } \\
& Long Term & Adj. Cost w/ \\
& Gain (\%) & No Capital Mobility (\%) \\
\hline Real Value Added & 1.22 & -10.98 \\
Welfare & 0.63 & -4.50 \\
\hline
\end{tabular}

Table 15: Welfare Changes (in \%) of Workers Who Were Employed in HT Manufacturing The Year Before The Shock - Comparison of Different Labor Market Policies (Under Perfect Capital Mobility)

\begin{tabular}{lcccc}
\hline & No Policy & Retraining & Subsidy & Zero Costs \\
\hline Overall & -13.7 & -9.4 & -11.7 & -3.7 \\
\hline \multicolumn{5}{c}{ By Demographics } \\
\hline Old / Unskilled & -12.3 & -2.8 & -10.9 & 10.5 \\
Old / Skilled & -9.4 & -1.1 & -4.9 & 3.5 \\
Young / Unskilled & -15.6 & -9.3 & -15.3 & -2.4 \\
Young / Skilled & -14.1 & -11.5 & -10.7 & -6.5 \\
\hline
\end{tabular}


Table 16: Adjustment Costs Under Different Labor Market Policies and Perfect Capital Mobility

\begin{tabular}{lccccc}
\hline & Long-Term & \multicolumn{3}{c}{ Adjustment Costs \% } \\
& Gain (\%) & No Policy & Retraining & Subsidy & Zero Costs \\
\hline Real Value Added & 3.24 & 11.77 & 11.79 & 11.16 & 16.57 \\
Welfare & 1.63 & 15.78 & 8.40 & 16.28 & 22.35 \\
\hline
\end{tabular}

Table 17: Long Run Elasticities of Employment and Wages in High-Tech Manufacturing

\begin{tabular}{llclc}
\hline & \multicolumn{2}{l}{ Perfect Capital Mobility } & \multicolumn{2}{l}{ Fixed Capital } \\
\hline Magnitude of the Adverse Shock & $10 \%$ & $30 \%$ & $10 \%$ & $30 \%$ \\
Employment & 7.04 & 3.26 & 1.34 & 1.35 \\
Human Capital Price - Unskilled & 1.25 & 1.28 & 0.12 & 0.14 \\
Human Capital Price - Skilled & 1.26 & 1.33 & 0.15 & 0.17 \\
\hline
\end{tabular}




\section{Figures}

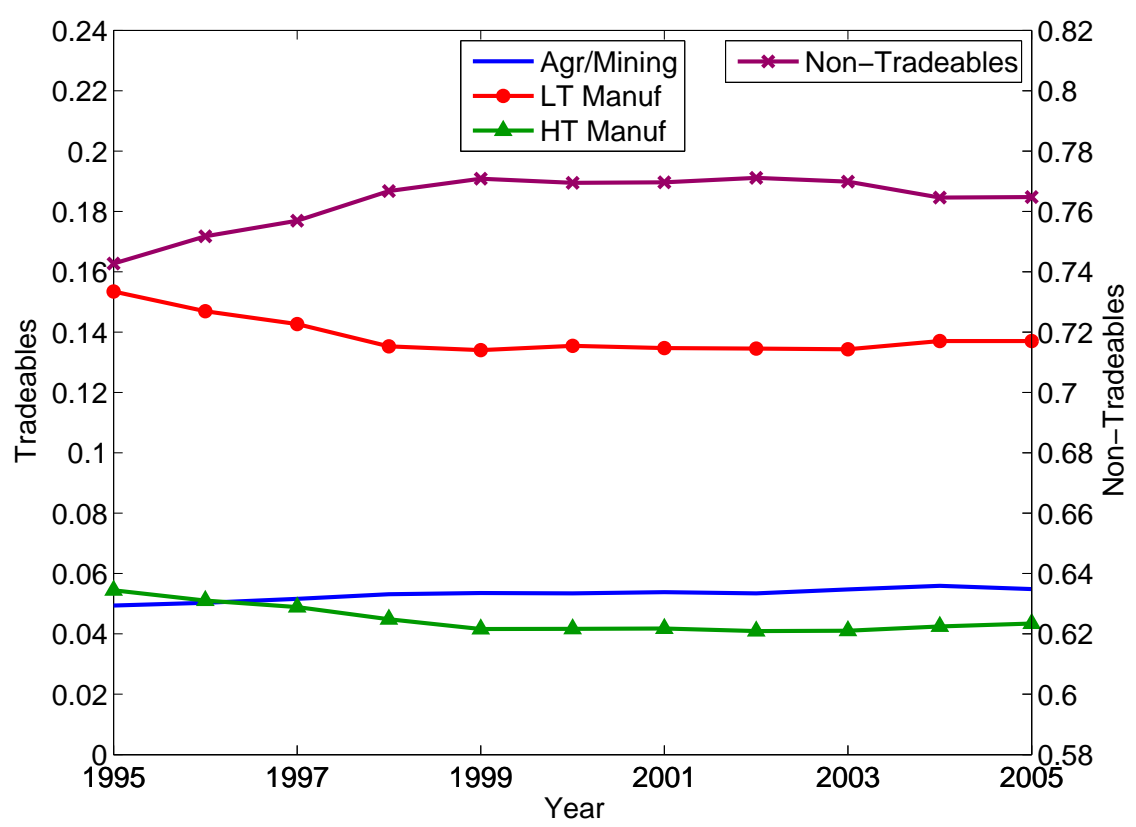

Figure 1: Evolution of employment shares 1995 to 2005 (Non-Tradeables: Right Axis)

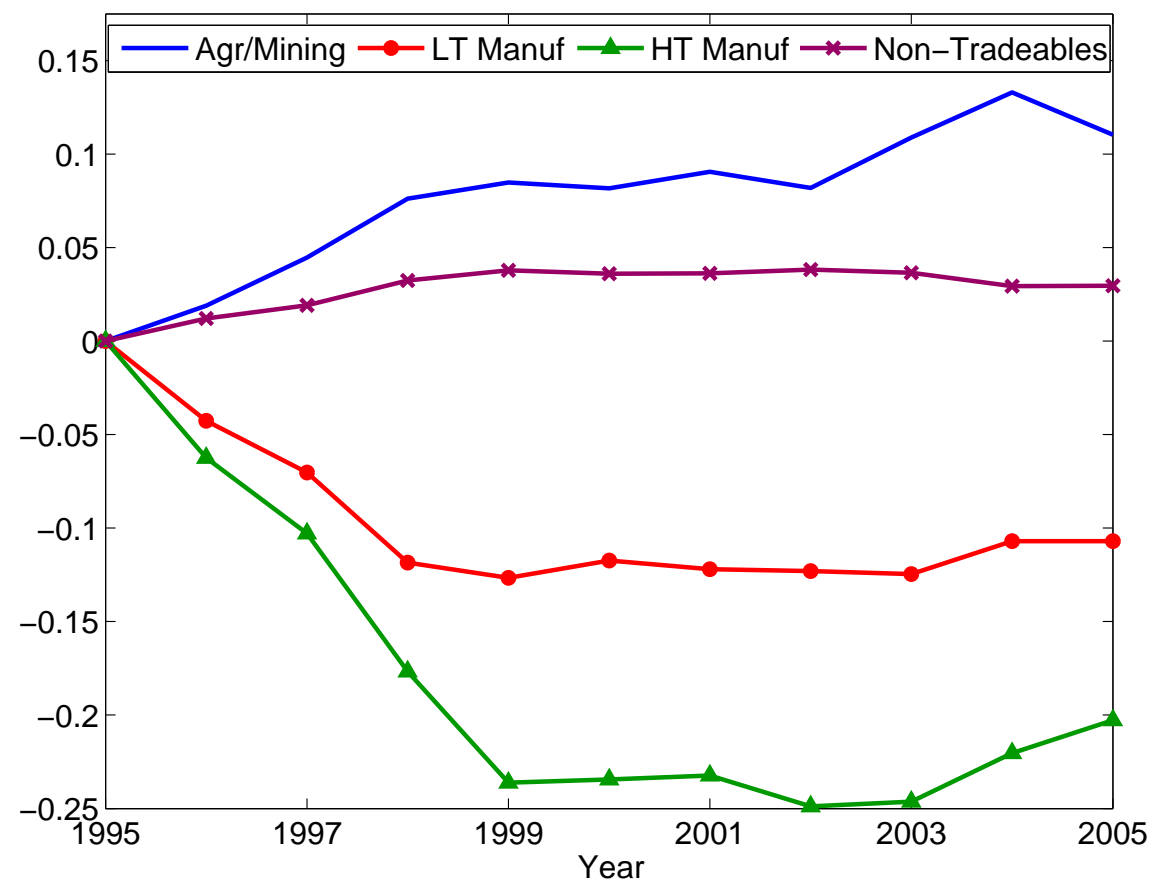

Figure 2: Relative changes in employment shares with respect to 1995. employment share $e_{t}$-employment share 1995

employment share 1995 


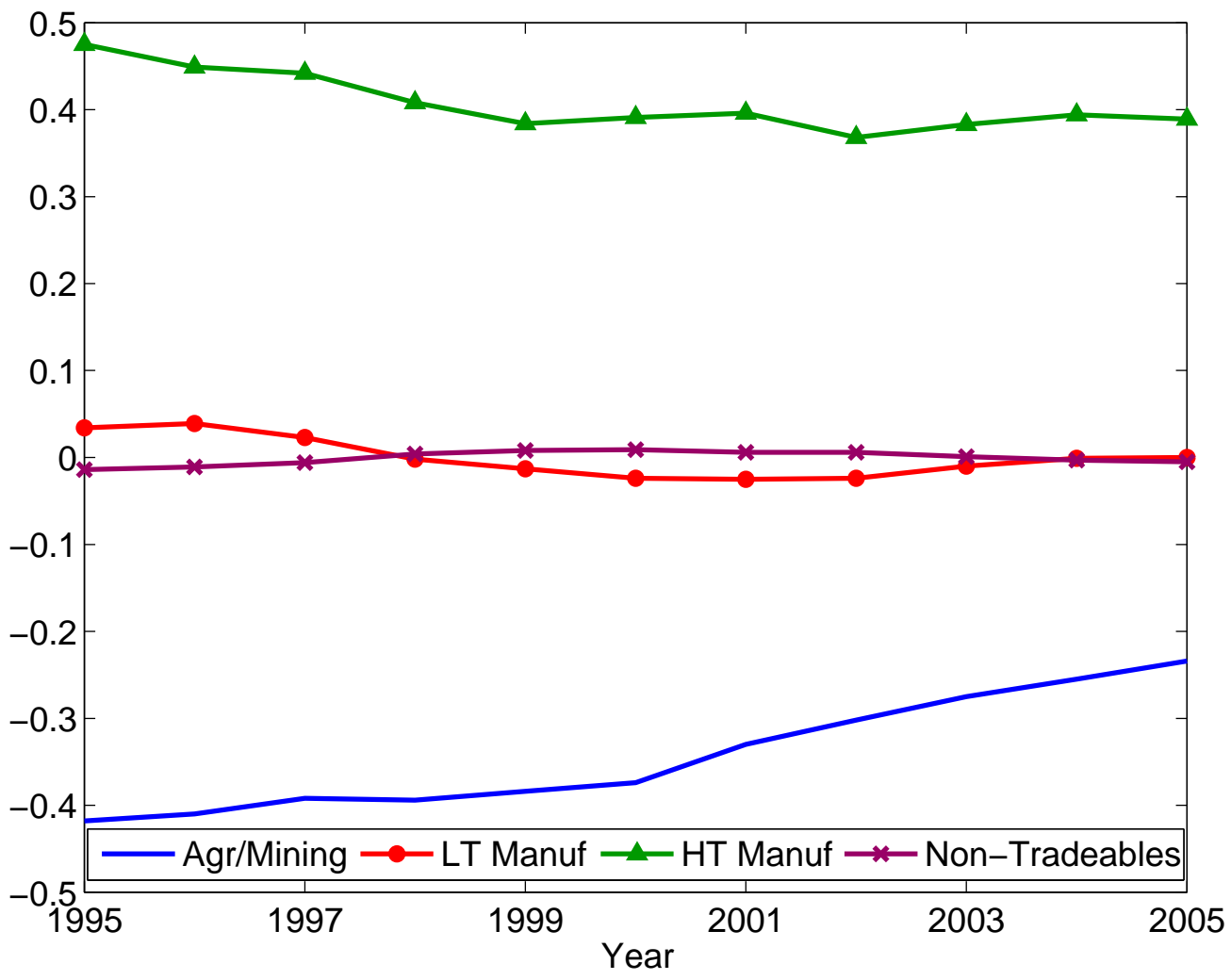

Figure 3: Evolution of wage differentials, 1995 to 2005 


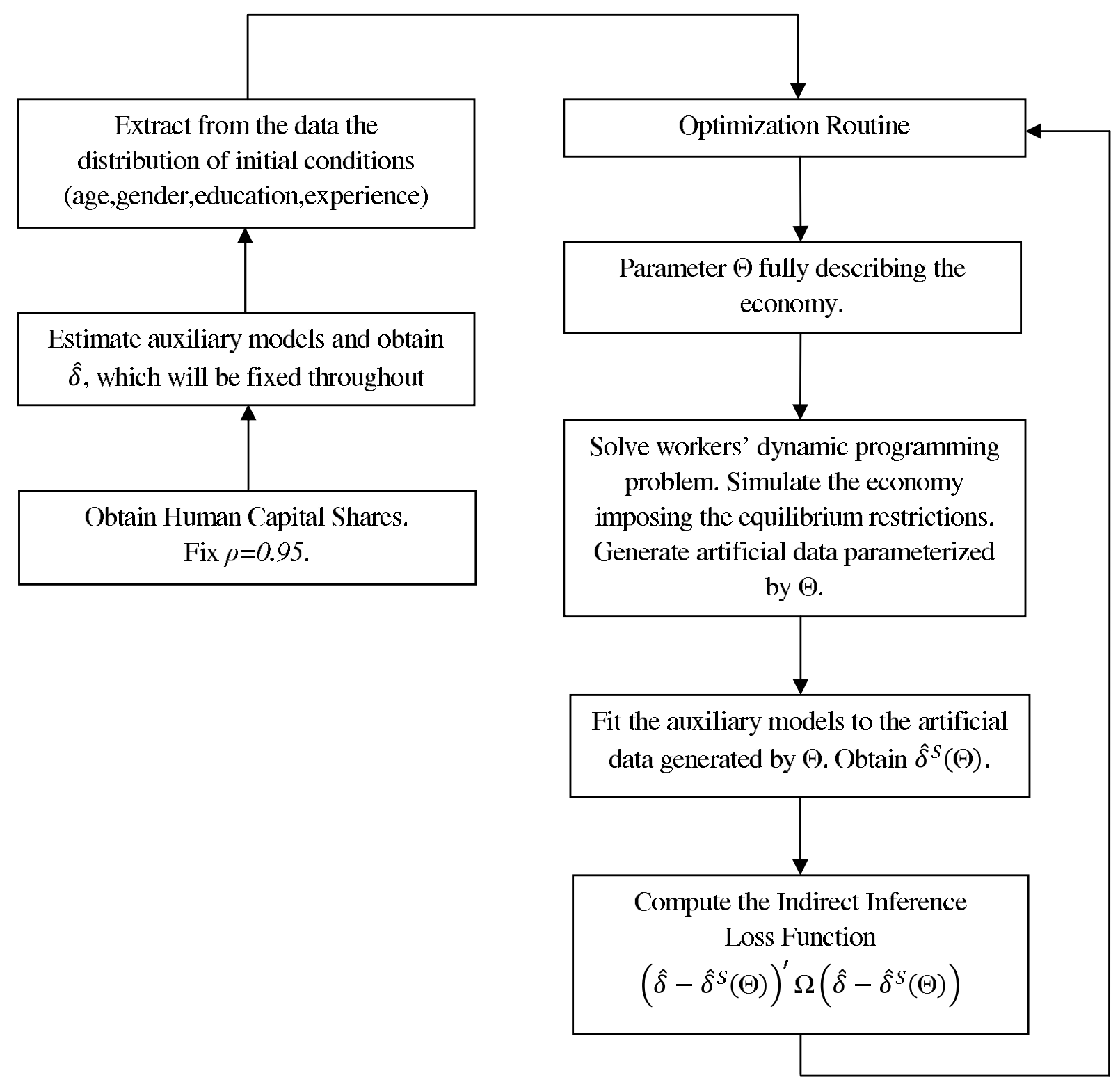

Figure 4: Estimation procedure 

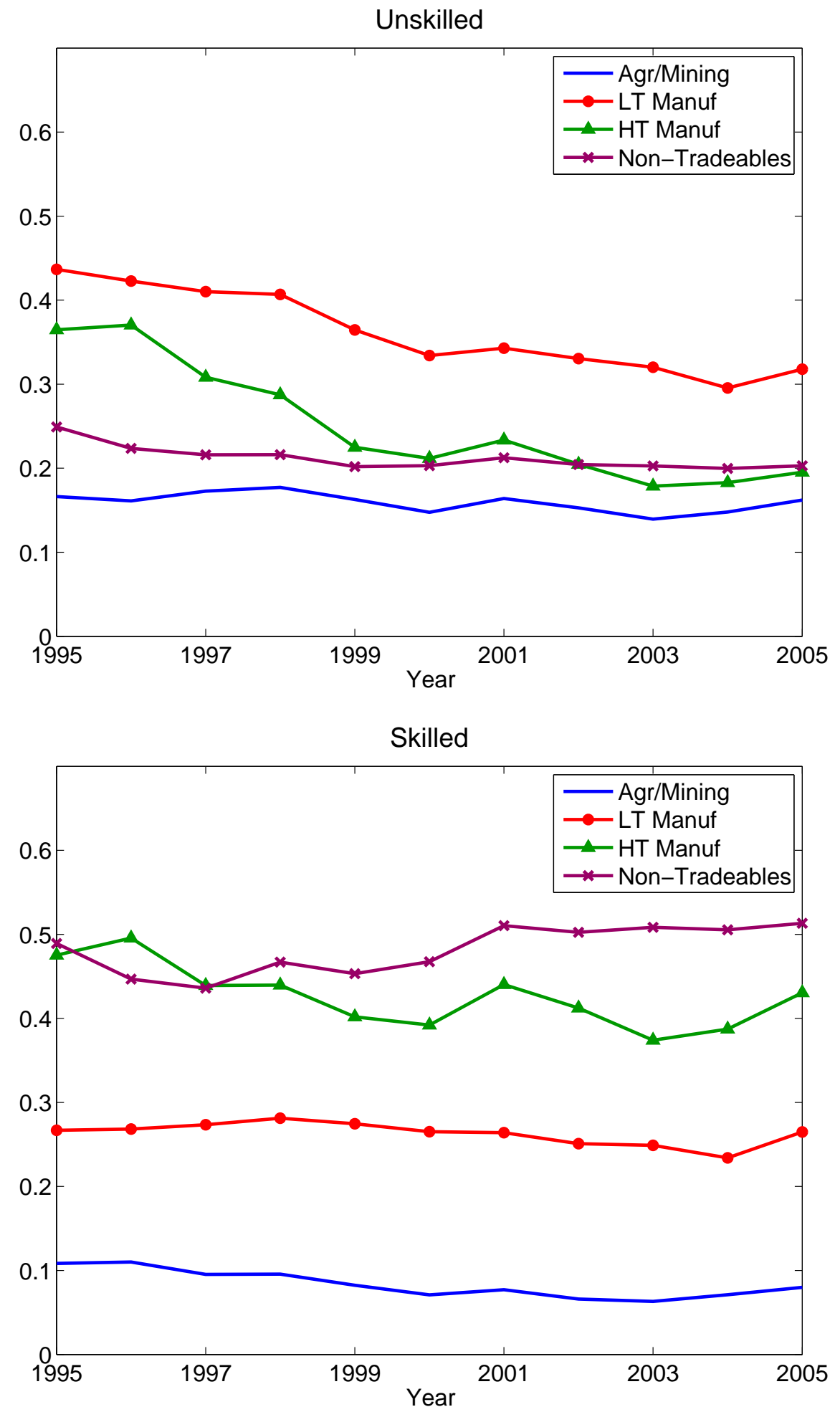

Figure 5: Evolution of human capital shares from Unskilled and Skilled workers, 1995 to 2005 

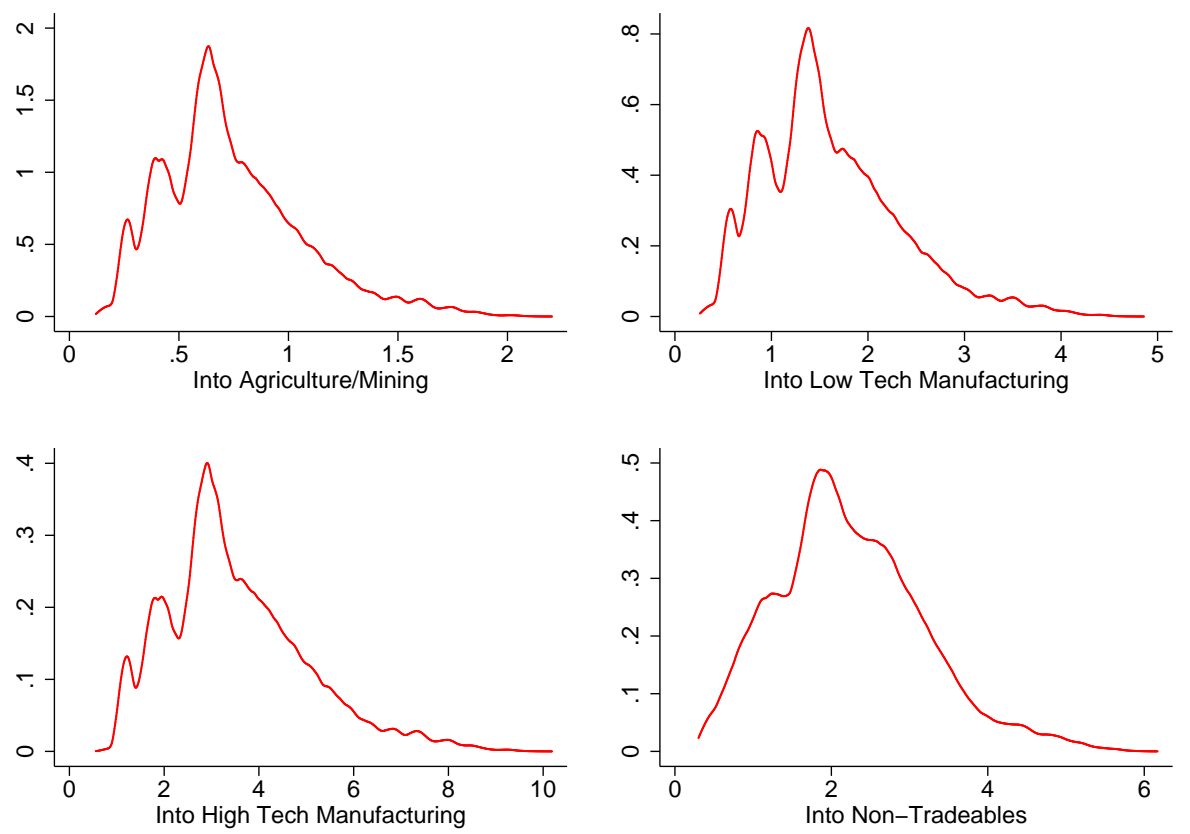

(a) From the Formal Sector
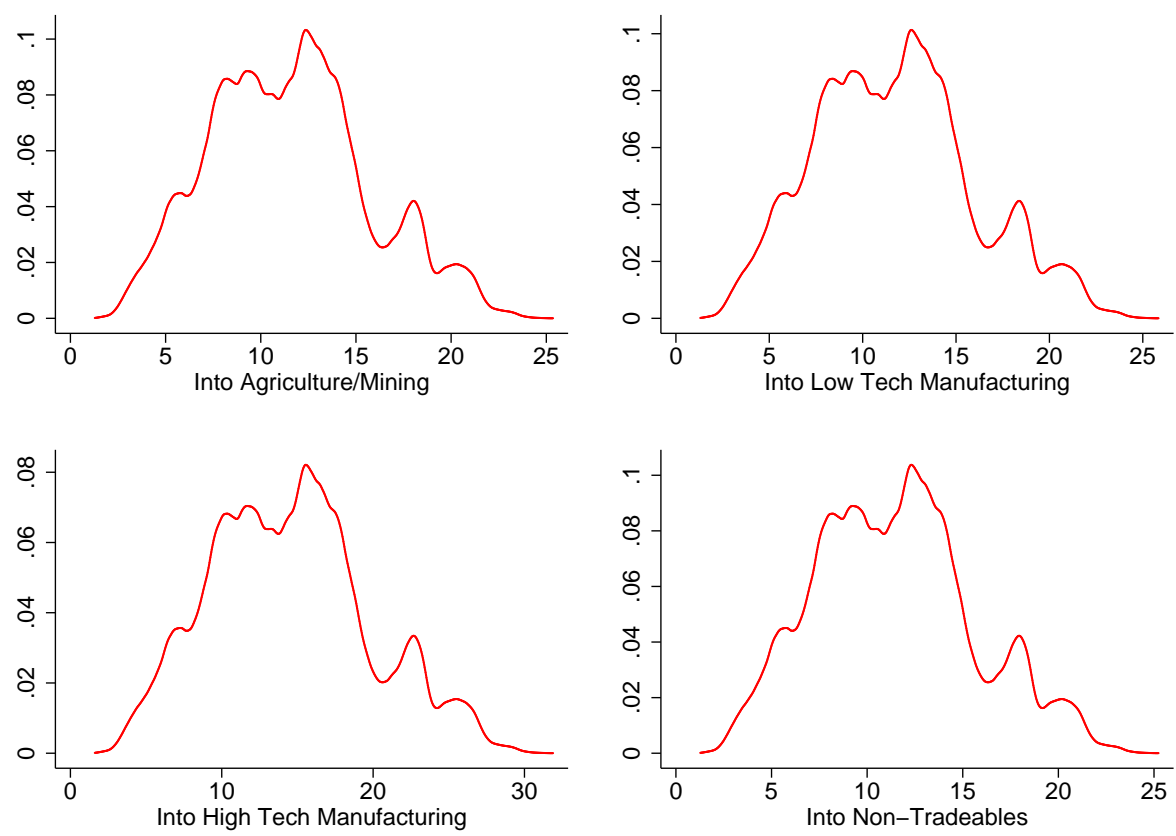

(b) From the Residual Sector

Figure 6: Nonparametric density plots of mobility costs expressed in terms of annual average wages. Costs of mobility vary according to the sector of destination and whether a worker is located in the formal sector or the Residual Sector. Costs also depend on workers' characteristics, the distribution of which is extracted from the data. 

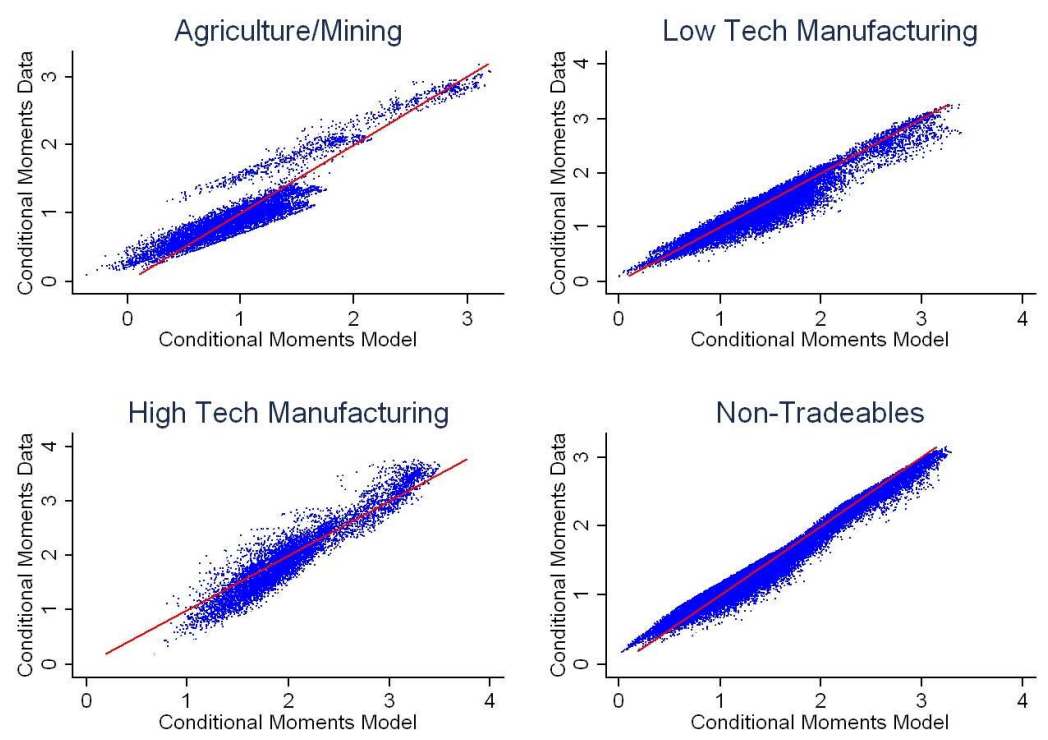

Figure 7: Goodness of Fit - Log Wage Regressions. The vertical axis displays the conditional log wage moments in the data. The horizontal axis displays the conditional log wage moments predicted by the model. The distribution of the conditioning variables is extracted from the data. A perfect model fit would lead to all the points over the $45^{\circ}$ line.
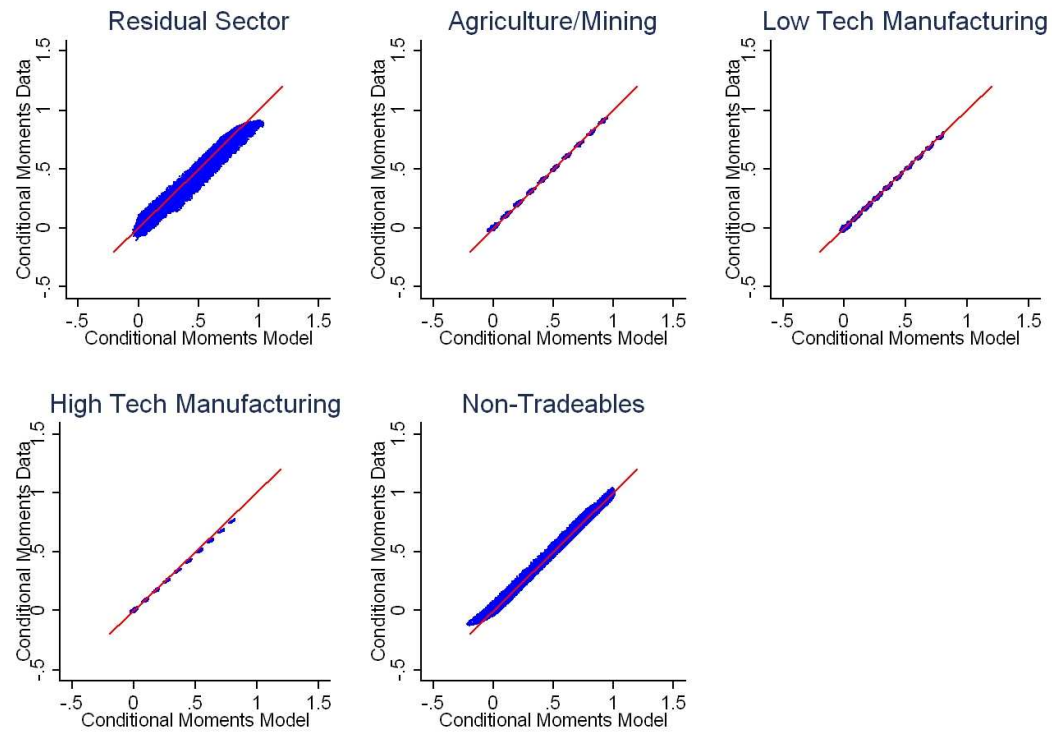

Figure 8: Goodness of Fit - Sectoral Choice Regressions. The vertical axis displays the conditional choice moments in the data. The horizontal axis displays the conditional choice moments predicted by the model. The distribution of the conditioning variables is extracted from the data. A perfect model fit would lead to all the points over the $45^{\circ}$ line. 

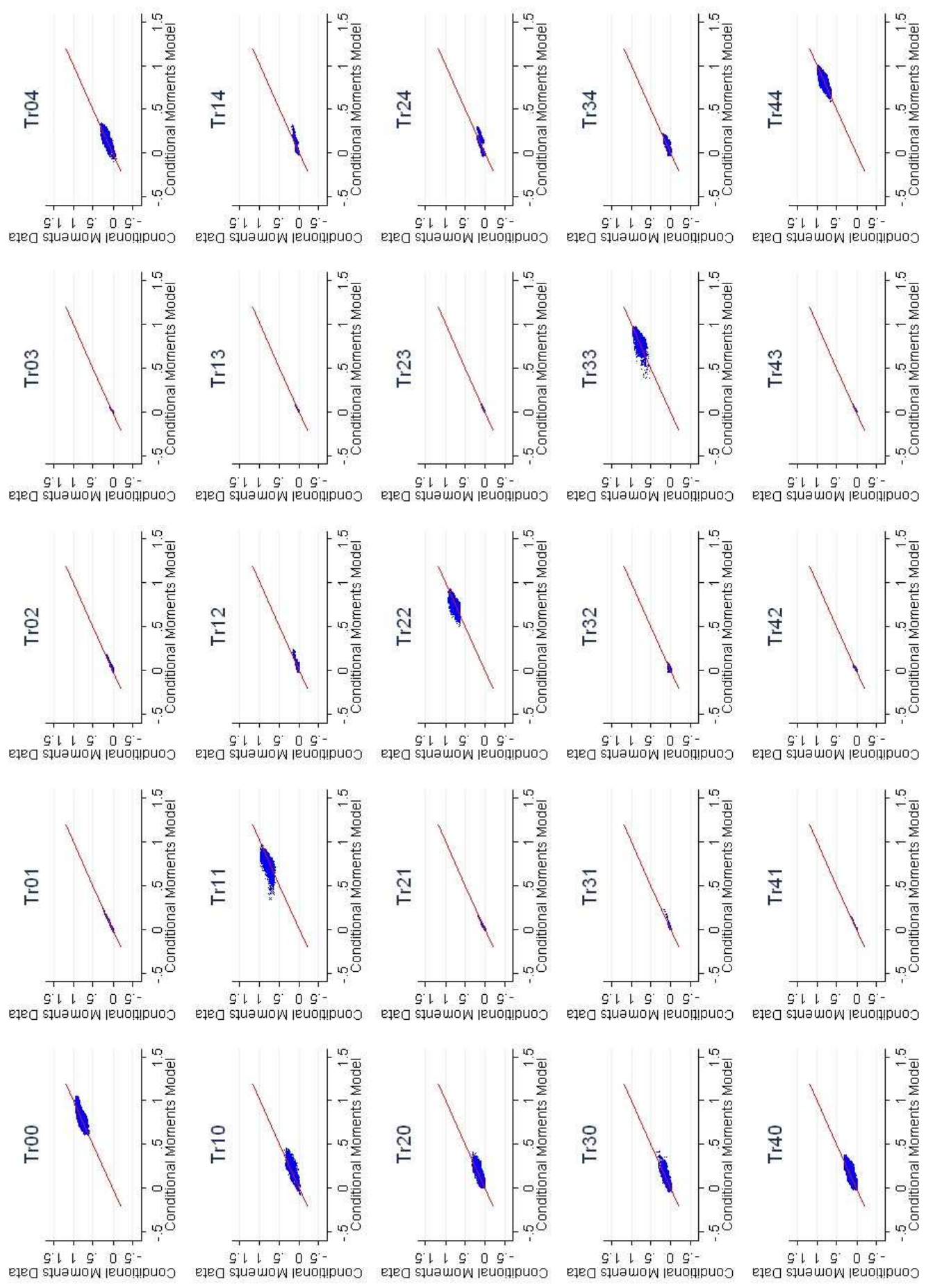

Figure 9: Goodness of Fit - Transition Rates Regressions. The vertical axis displays the conditional transition moments in the data. The horizontal axis displays the conditional transition moments predicted by the model. The distribution of the conditioning variables is extracted from the data. A perfect model fit would lead to all the points over the $45^{\circ}$ line. 

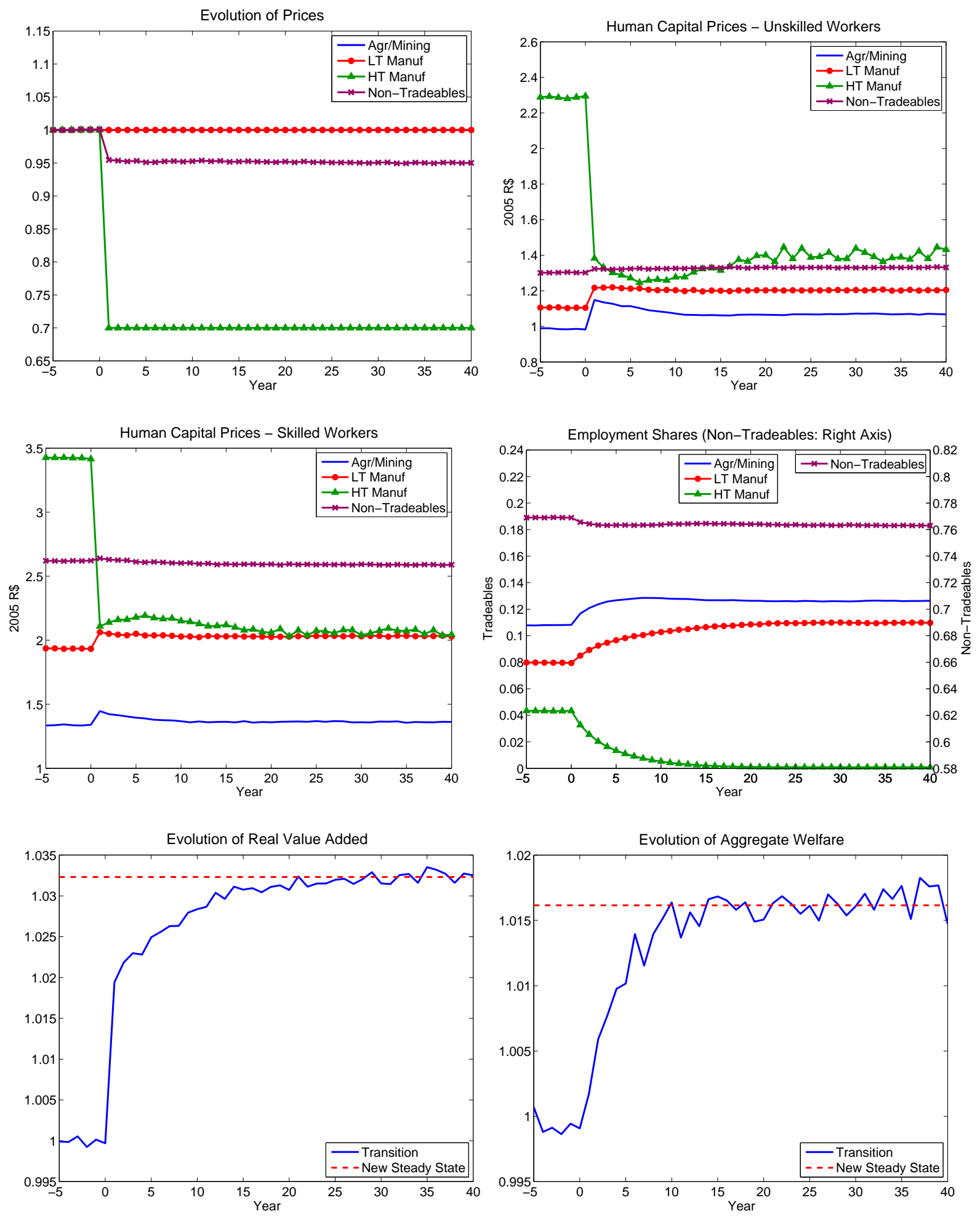

Figure 10: Dynamics under Perfect Capital Mobility following the adverse price shock in the High-Tech Manufacturing sector illustrated in the left-upper panel. The price in the Non-Tradeables sector adjusts in equilibrium. The evolution of human capital prices, employment shares, real value added and aggregate welfare following the shock are subsequently displayed in that order. 

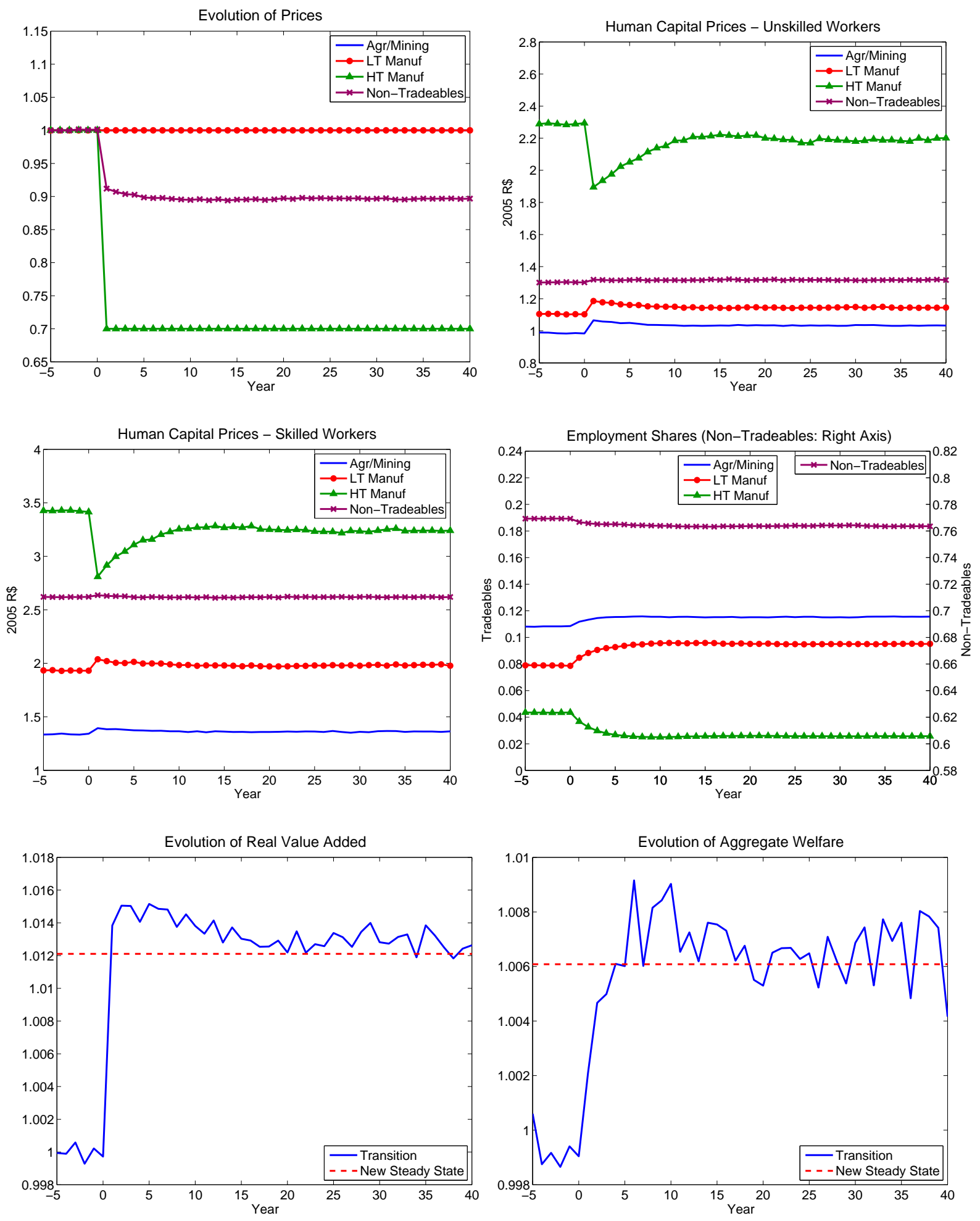

Figure 11: Dynamics under No Capital Mobility following the adverse price shock in the HighTech Manufacturing sector illustrated in the left-upper panel. The price in the Non-Tradeables sector adjusts in equilibrium. The evolution of human capital prices, employment shares, real value added and aggregate welfare following the shock are subsequently displayed in that order. 

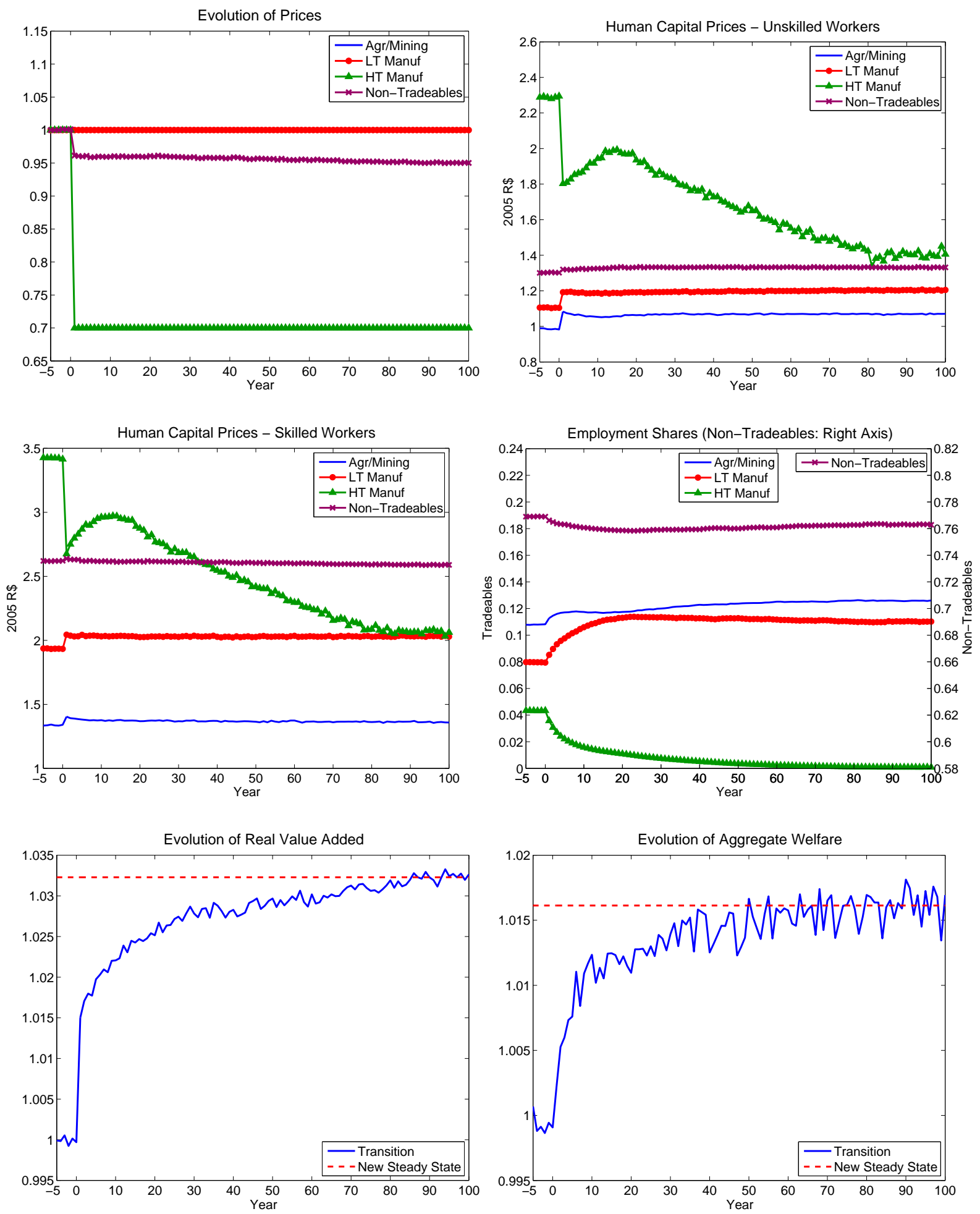

Figure 12: Dynamics under Imperfect Capital Mobility following the adverse price shock in the High-Tech Manufacturing sector illustrated in the left-upper panel. The price in the Non-Tradeables sector adjusts in equilibrium. The evolution of human capital prices, employment shares, real value added and aggregate welfare following the shock are subsequently displayed in that order. 


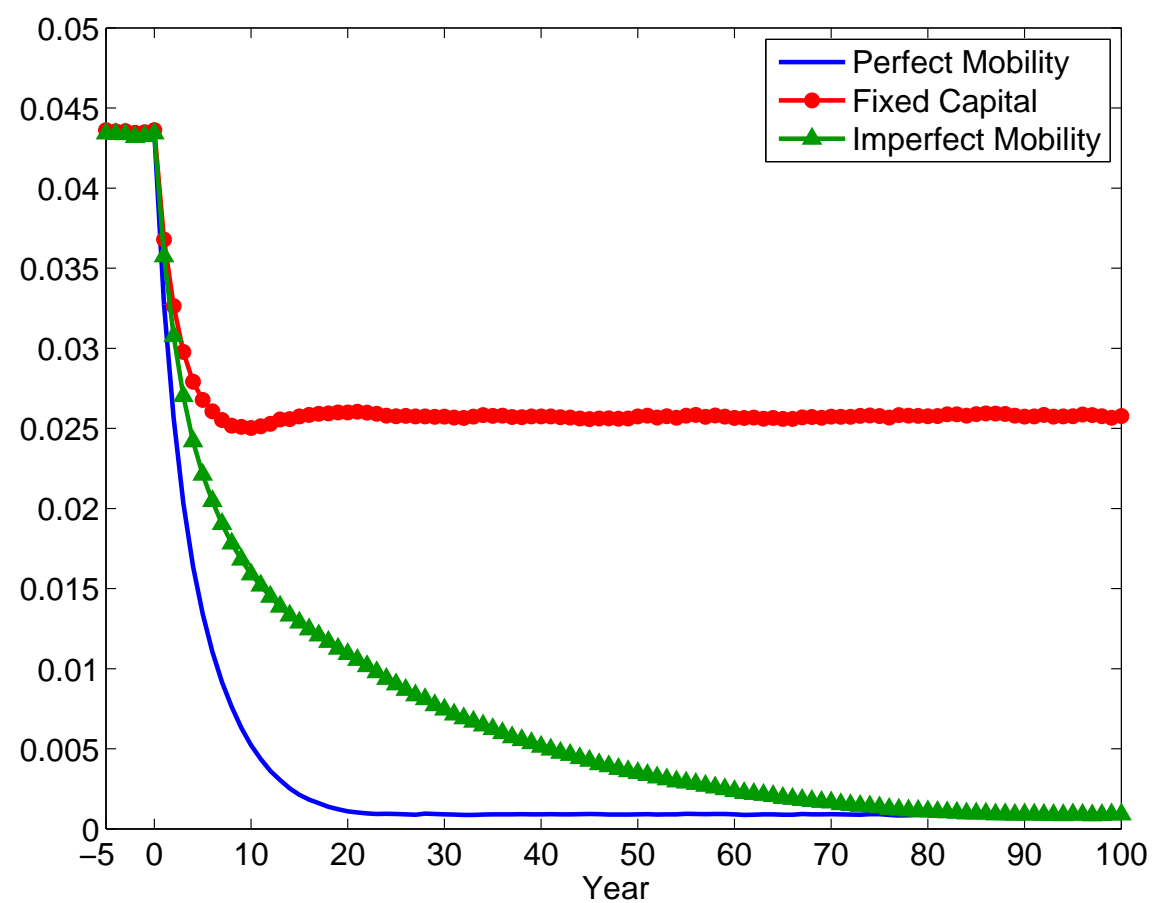

Figure 13: Evolution of employment shares in the HT Manufacturing sector following the adverse price shock and under the different assumptions regarding capital mobility

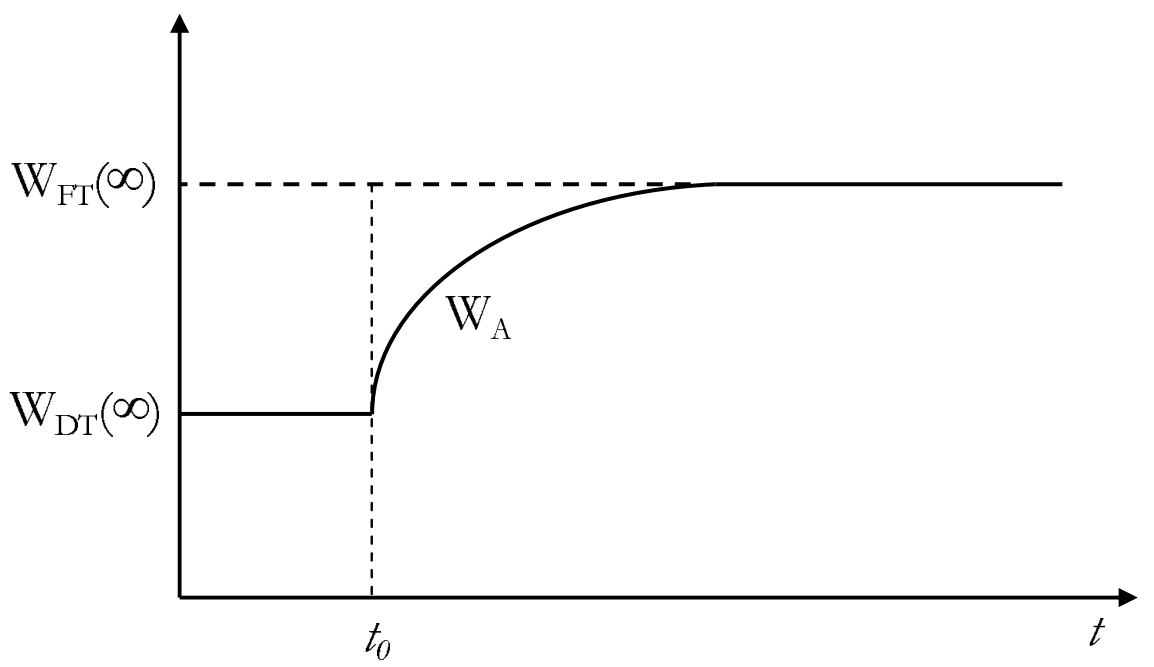

Figure 14: Slow and Gradual Adjustment of Welfare $W_{A}$ From The Distorted Trade level $W_{D T}(\infty)$ to the Free Trade Steady State level $W_{F T}(\infty)$ 


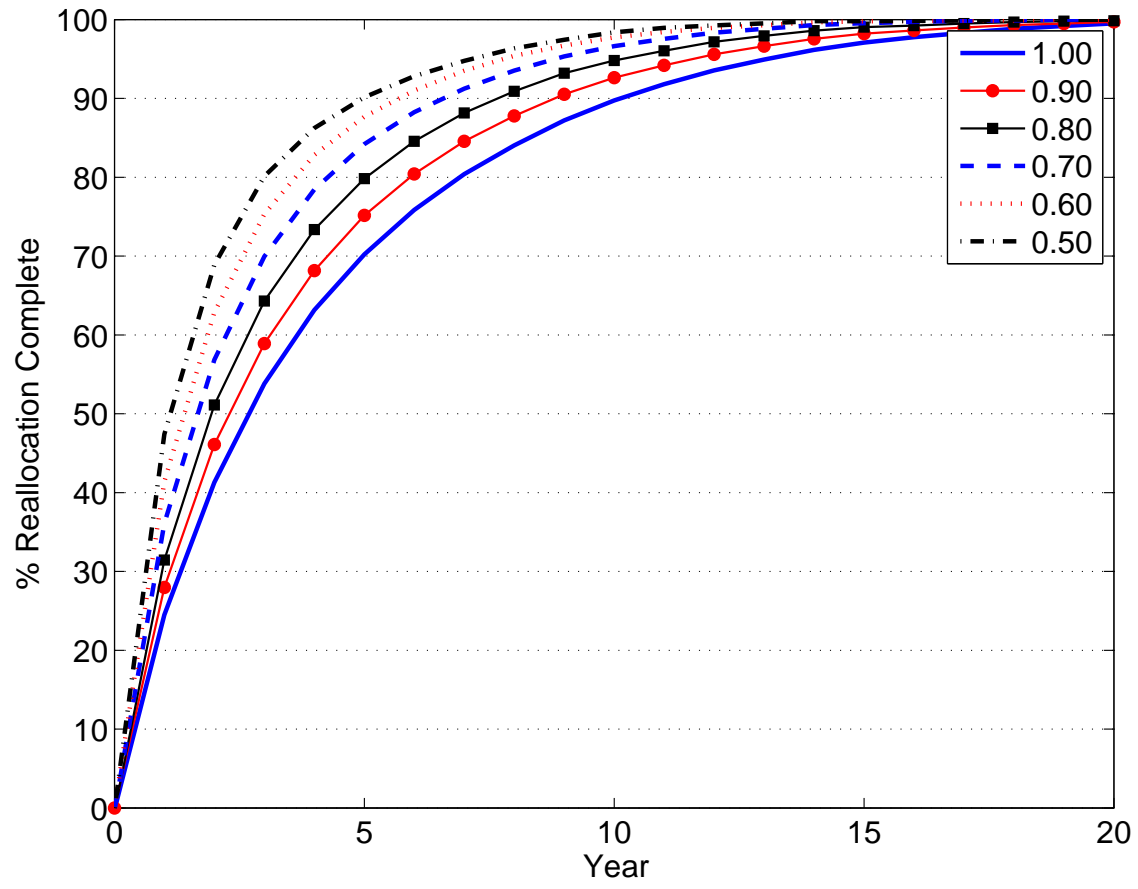

Figure 15: Reallocation speed out of the HT Manufacturing sector following the adverse price shock for different levels of mobility costs. Perfect Capital Mobility is assumed. 

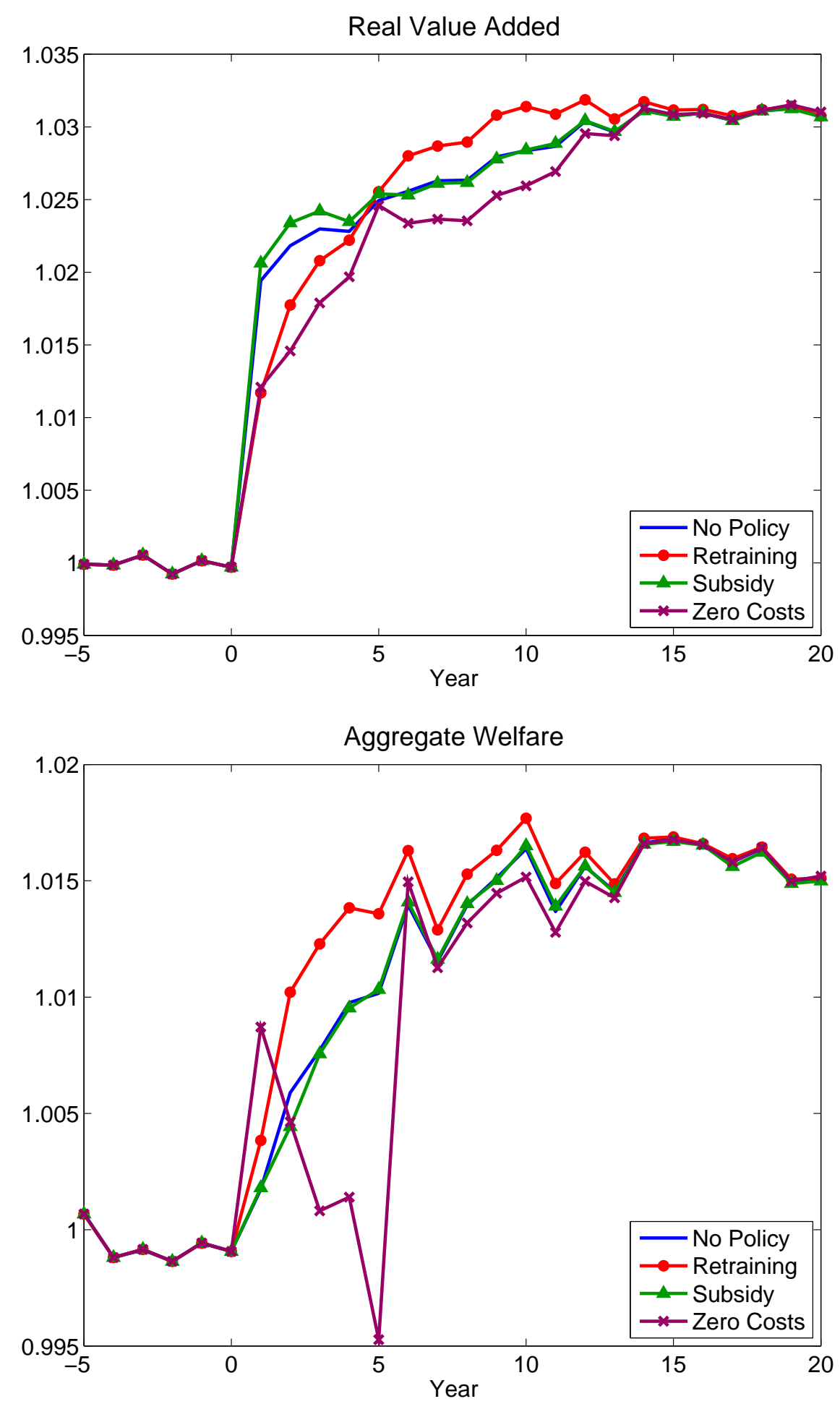

Figure 16: Welfare dynamics following the price shock under the different labor market policies. Perfect Capital Mobility is assumed. 


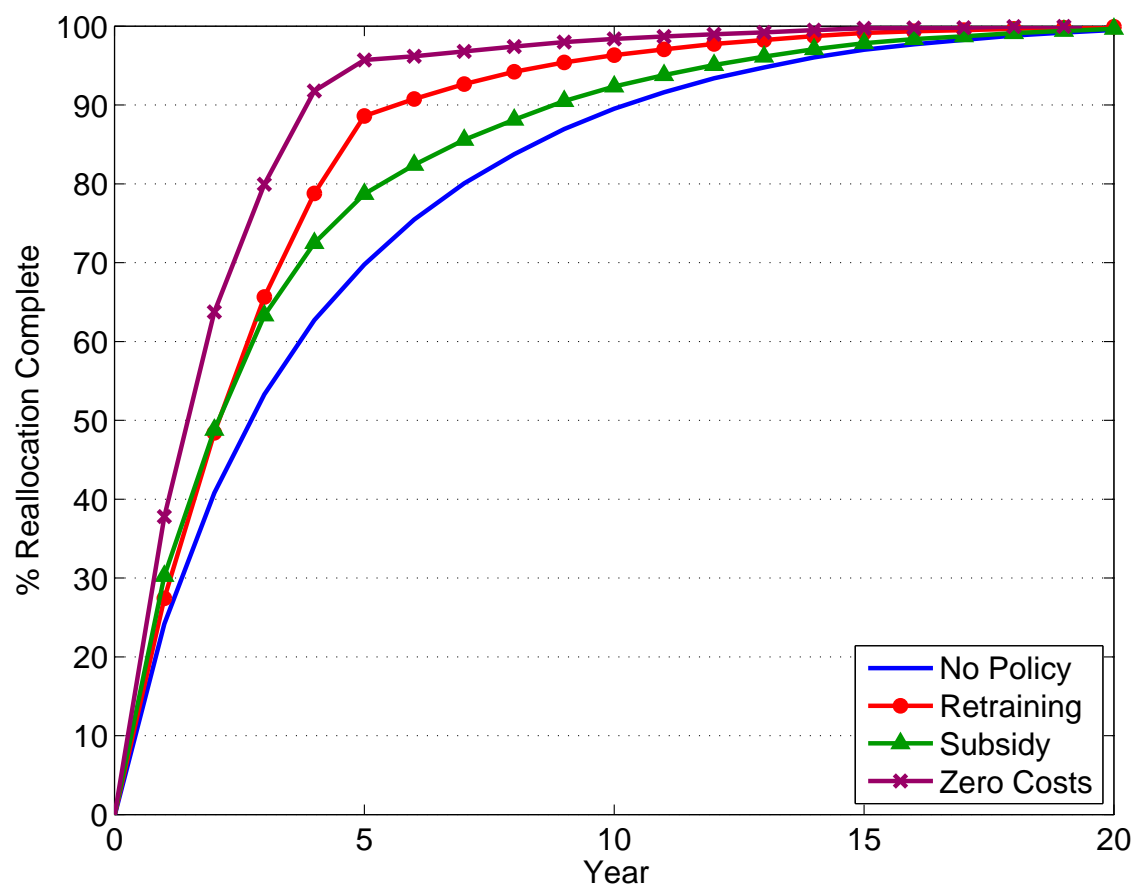

Figure 17: Reallocation speed out of the HT Manufacturing sector following the adverse price shock under the different labor market policies. Perfect Capital Mobility is assumed. 


\section{A Appendix - Solving The Bellman Equation}

Given a parameter set $\Theta$ that parametrizes the economy described in Section 2, the distribution of initial conditions across the population, and real value added series for each sector, we can simulate individual choices and compute the sector-specific equilibrium human capital prices as described in Section 2.3.

The parameter set $\Theta$ includes the parameters of the value added functions (1), human capital production functions (7), idiosyncratic shocks' variances, mobility costs functions (9) and discount factor.

The distribution of initial conditions is given by the joint distribution of gender, education, age and sector-specific experiences as found in the data in the first sample period, 1995. From 1996 onwards, I need to include the initial conditions of entering generations (those who are 25 years old) and keep track of the decisions generated by the model of the older generations.

In order to simulate the individual decisions for the parameter set $\Theta$, I must first solve the Bellman equation given by (11)-(12). The Bellman equation is solved by backward recursion, starting at the terminal age $A=60$ and going back until the initial age of 25 is reached. Some difficulties arise in the solution of (11)-(12). First, in order to compute expectations, I must integrate the value function - which is a nonlinear function of the state space variables - with respect to the idiosyncratic shocks. Such multidimensional integrals do not have a closed form solution and hence must be approximated. Second, remember that the returns to skill $\left\{r_{t}^{0, k}\right\}_{k=1}^{4}$ or $\left\{r_{t}^{1, k}\right\}_{k=1}^{4}$ are included in the state space and these are continuous variables. Consequently, I have a large state space with continuous variables.

In order to deal with these problems in a way that still makes estimation feasible, I approximate the solution of the Bellman equation using similar methods as in Keane and Wolpin (1994).

Consider a worker with gender $g$ and education level $e$. That worker has accumulated sector-specific experience in each sector given by the vector exper and human capital prices for her skill level are given by the vector $\mathbf{r}$. In addition, suppose this worker has age $a$ and chose sector $s$ last period. Let $E M A X_{a}(g, e$, exper, $\mathbf{r}, s)$ denote the expected value this worker gets at age $a$, before the idiosyncratic shocks are revealed and before the age $a$ choice is made. $E M A X_{a}($.$) stands for the expectation of V_{a}($.$) , the left hand side object in (12),$ with respect to the idiosyncratic shocks.

Let

$$
\Delta=\left\{\left(\operatorname{exper}^{1}, \ldots, \text { exper }^{4}, r^{1}, \ldots, r^{4}\right) \mid \sum_{s=1}^{4} \operatorname{exper}^{s} \leq 9 ; \underline{r} \leq r^{s} \leq \bar{r}\right\}
$$


$\underline{r}$ and $\bar{r}$ are lower and upper bounds for prices of human capital. For each age $a$, gender $g$, education level $e$ and sector $s$, I approximate $E M A X_{a}(g, e, ., s)$, defined on $\Delta$ with the following backward recursion procedure.

Repeat the following algorithm for all $g \in\{$ Male, Female $\}, e \in\{1,2,3,4\}$ and $s \in$ $\{0,1,2,3,4\}$.

1) Start with $a=A=60$. Draw $N=1500$ points at random

$$
\left\{\boldsymbol{\delta}^{n} \equiv\left(\operatorname{exper}^{1, n}, \ldots, \operatorname{exper}^{4, n}, r^{1, n}, \ldots, r^{4, n}\right)\right\}_{n=1}^{N} \in \Delta
$$

For each $n$, approximate $E M A X_{A}\left(g, e, \boldsymbol{\delta}^{n}, s\right)$ drawing idiosyncratic shocks $\varepsilon$ and using Monte Carlo integration.

2) Approximate $\operatorname{EMAX}_{A}(g, e, ., s)$ by fitting a complete second-order polynomial regression of $\left\{E M A X_{A}\left(g, e, \boldsymbol{\delta}^{n}, s\right)\right\}_{n=1}^{N}$ on $\left\{\begin{array}{c}1, \operatorname{exper}^{1, n}, \ldots, \operatorname{exper}^{4, n}, r^{1, n}, \ldots, r^{4, n}, \\ r^{1, n} I\left(r^{1, n}>c^{1}\right), \ldots, r^{4, n} I\left(r^{4, n}>c^{4}\right)\end{array}\right\}$

3) Use equations (11)-(12) and repeat this procedure for $a=A-1, \ldots, 26$.

Ideally, $c_{1}, \ldots, c_{S}$ should be chosen so as to obtain the best possible fit, but in this paper, I set $c_{s}=\frac{\underline{r^{s}}+\overline{r^{s}}}{2}$ in order to save computational time. I get, nevertheless, very good fit for the polynomial regressions $\left(R^{2}>0.99\right.$ for all $g, e$ and $\left.s\right)$.

\section{B Appendix - Standard Errors}

The Indirect Inference estimator is defined by:

$$
\widehat{\Theta}=\arg \min _{\Theta}\left(\widehat{\delta}-\widehat{\delta}^{S}(\Theta)\right)^{\prime} \widehat{\Omega}\left(\widehat{\delta}-\widehat{\delta}^{S}(\Theta)\right)
$$

Where $\widehat{\Omega}$ is a positive definite matrix with $\Omega=p \lim \widehat{\Omega}$

Since the model is assumed to be correctly specified:

$$
\delta_{0} \equiv p \lim \widehat{\delta}=\delta\left(\Theta_{0}\right)
$$

Define

$$
\begin{gathered}
\widetilde{g}^{S}(\Theta) \equiv \widehat{\delta}-\widehat{\delta}^{S}(\Theta) \\
\widetilde{g}^{S}\left(\Theta_{0}\right)=\widehat{\delta}-\delta_{0}+\delta_{0}-\widehat{\delta}^{S}\left(\Theta_{0}\right)
\end{gathered}
$$




$$
\begin{aligned}
\sqrt{N} \widetilde{g}^{S}\left(\Theta_{0}\right) & =\sqrt{N}\left(\widehat{\delta}-\delta_{0}\right)+\sqrt{N}\left(\widehat{\delta}^{S}\left(\Theta_{0}\right)-\delta_{0}\right) \\
& =\sqrt{N}\left(\widehat{\delta}-\delta_{0}\right)+\frac{\sqrt{N^{S}}}{\sqrt{S}}\left(\widehat{\delta}^{S}\left(\Theta_{0}\right)-\delta_{0}\right) \\
& \Rightarrow N\left(0, A V A R(\widehat{\delta})+\frac{1}{S} A V A R\left(\widehat{\delta}^{S}\left(\Theta_{0}\right)\right)\right)
\end{aligned}
$$

The first order condition to the minimization problem is:

$$
\frac{\partial \widetilde{g}^{S}(\widehat{\Theta})}{\partial \Theta} \widehat{\Omega} \widetilde{g}^{S}(\widehat{\Theta})=0
$$

The mean value theorem applied to $\widetilde{g}^{S}(\widehat{\Theta})$ gives:

$$
\left(\frac{\partial \widetilde{g}^{S}(\widehat{\Theta})}{\partial \Theta}\right)^{\prime} \widehat{\Omega}\left(\widetilde{g}^{S}\left(\Theta_{0}\right)+\left(\frac{\partial \widetilde{g}^{S}(\bar{\Theta})}{\partial \Theta}\right)\left(\widehat{\Theta}-\Theta_{0}\right)\right)=0
$$

Where $\bar{\Theta} \in\left[\Theta_{0}, \widehat{\Theta}\right]$.

$$
\sqrt{N}\left(\widehat{\Theta}-\Theta_{0}\right)=\left[\left(\frac{\partial \widetilde{g}^{S}(\widehat{\Theta})}{\partial \Theta}\right)^{\prime} \widehat{\Omega}\left(\frac{\partial \widetilde{g}^{S}\left(\Theta_{0}\right)}{\partial \Theta}\right)\right]^{-1}\left(\frac{\partial \widetilde{g}^{S}(\bar{\Theta})}{\partial \Theta}\right)^{\prime} \widehat{\Omega} \sqrt{N} \widetilde{g}^{S}\left(\Theta_{0}\right)
$$

Taking the limit $N \rightarrow \infty$ (which implies $S \times N \rightarrow \infty$, for $S$ fixed), we have:

$$
\begin{gathered}
\frac{\partial \widetilde{g}^{S}(\widehat{\Theta})}{\partial \Theta} \stackrel{p}{\rightarrow} E\left[\frac{\partial g\left(\Theta_{0}\right)}{\partial \Theta}\right] \equiv G_{0} \\
\sqrt{N}\left(\widehat{\Theta}-\Theta_{0}\right) \Rightarrow N\left(0,\left(G_{0}^{\prime} \Omega G_{0}\right)^{-1} G_{0}^{\prime} \Omega\left[A V A R(\widehat{\delta})+\frac{1}{S} A V A R\left(\widehat{\delta}^{S}\left(\Theta_{0}\right)\right)\right] \Omega G_{0}\left(G_{0}^{\prime} \Omega G_{0}\right)^{-1}\right)
\end{gathered}
$$

Consequently:

$$
\operatorname{Var}\left(\widehat{\Theta}-\Theta_{0}\right) \approx\left(G_{0}^{\prime} \Omega G_{0}\right)^{-1} G_{0}^{\prime} \Omega\left[\frac{A V A R(\widehat{\delta})+\frac{1}{S} A V A R\left(\widehat{\delta}^{S}\left(\Theta_{0}\right)\right)}{N}\right] \Omega G_{0}\left(G_{0}^{\prime} \Omega G_{0}\right)^{-1}
$$


Plugging estimates for the above quantities:

$$
\begin{aligned}
& \widehat{A \operatorname{ARR}}(\widehat{\delta})=N \times \widehat{\operatorname{Var}(\widehat{\delta})}
\end{aligned}
$$

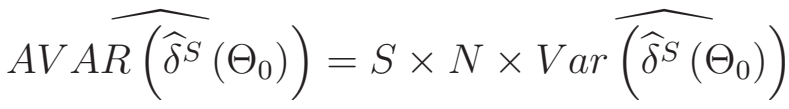

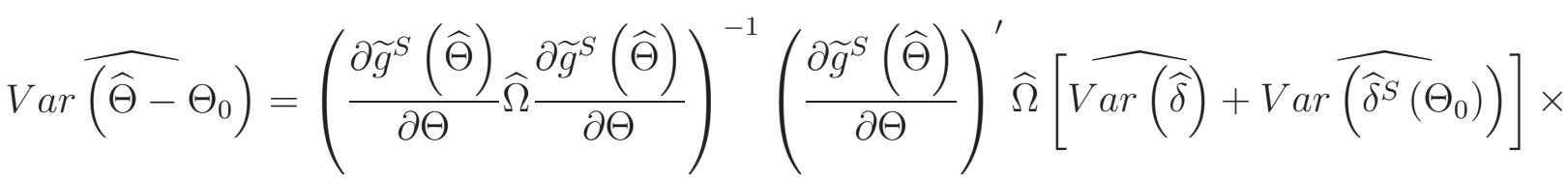

$$
\begin{aligned}
& \widehat{\Omega}\left(\frac{\partial \widetilde{g}^{S}(\widehat{\Theta})}{\partial \Theta}\right)\left(\frac{\partial \widetilde{g}^{S}(\widehat{\Theta})}{\partial \Theta} \widehat{\Omega} \frac{\partial \widetilde{g}^{S}(\widehat{\Theta})}{\partial \Theta}\right)^{-1}
\end{aligned}
$$

Although $\widehat{\operatorname{Var}(\widehat{\delta})}$ can be computed using the $G M M$ equations that define $\widehat{\delta}$, the size of the problem makes the asymptotic variance have a very cumbersome expression. For this reason, $\widehat{\operatorname{Var}(\widehat{\delta})}$ will be computed by bootstrap.

Since the model is assumed to be correctly specified, $\operatorname{Var} \widehat{\left(\widehat{\delta}^{S}\left(\Theta_{0}\right)\right)}$ can also be computed by bootstrap with the original data. The procedure is as follows: 1) extract 1000 individuals per generation and skill level from 1995 to 2005. 2) Repeatedly draw these individuals with replacement. 3) For each drawn sample $j$, fit $\widehat{\delta}^{j}=\left(X^{j \prime} W X^{j}\right)^{-1} X^{j \prime} W Y^{j}$, where $W$ is a weighting matrix that corrects for the sampling scheme.

\section{B.1 Weighting Matrix}

$$
\widehat{W}=\left[\begin{array}{cccc}
\widehat{V(\widehat{\beta})}^{-1} & 0 & 0 & 0 \\
0 & \widehat{V(\widehat{\gamma})}^{-1} & 0 & 0 \\
0 & 0 & \widehat{V(\widehat{\varphi})}^{-1} & 0 \\
0 & 0 & 0 & {\widehat{V\left(\widehat{\sigma^{2}}\right)}}^{-1}
\end{array}\right]
$$

\section{B.2 Computation of $\mathrm{G}_{0}$}

1) For each component $n$ of $\Theta$, sample 20 points $\widehat{\Theta}+\varepsilon_{n} e_{n}$, where $\left|\varepsilon_{n}\right|$ is small and compute $\widehat{\delta}^{S}\left(\widehat{\Theta}+\varepsilon_{n} e_{n}\right)$.

2) Fit a second order polynomial of $\left\{\widehat{\delta}^{S}\left(\widehat{\Theta}+\varepsilon_{n} e_{n}\right)\right\}$ on $\left\{\widehat{\Theta}_{n}+\varepsilon_{n}\right\}$. 
3) Obtain an approximation for $\left.\frac{\partial \delta}{\partial \Theta_{n}}\right|_{\Theta=\widehat{\Theta}}$ by looking at the derivative of the polynomial at $\widehat{\Theta}_{n}$.

\section{Appendix - Goodness of Fit}

This appendix examines how the model performs relative to moments which were not imposed during the estimation. Three additional classes of moments are analyzed.

First, Figure C.18 shows three-year history transition rates in the data and in the simulated model. A three-year transition history between years $t$ and $t+2$ consists of chosen sectors $s(t), s(t+1)$ and $s(t+2)$. Each bullet in Figure C.18 represents the fraction of the population who switched from sector $s(t)$ to sector $s(t+1)$ and then $s(t+2)$, conditional on $s(t)$ and averaged out throughout the sample period. For example, a bullet can represent the transition $3 \rightarrow 0 \rightarrow 4$, which means a transition from High-Tech Manufacturing to the Residual Sector and then to Non-Tradeables. However, the transition rate is conditional on starting at High-Tech Manufacturing. The transition rate for $3 \rightarrow 0 \rightarrow 4$ should be read as: among those workers whose sector of origin is $3,1.4 \% / 1.5 \%$ (data / model) of them followed the $0 \rightarrow 4$ path in the subsequent years.

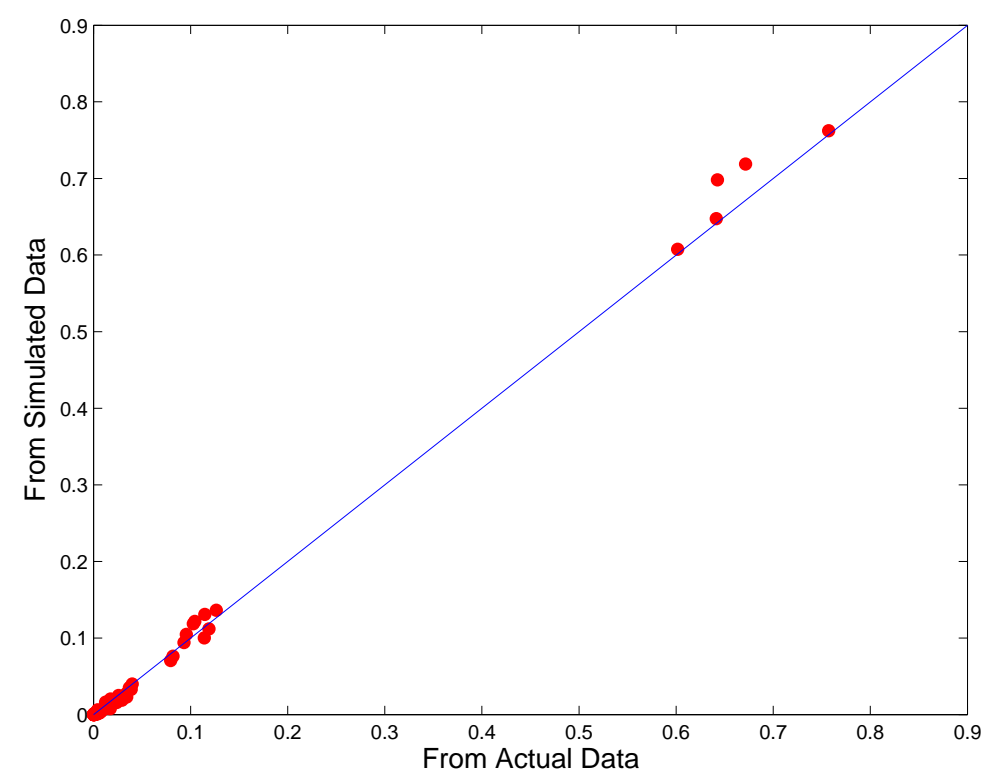

Figure C.18: Three-year history transition rates as predicted by the simulated model vs. actual rates in the data.

Second, Figure C.19 shows the frequency of switching for those individuals who are present in each of the 11 years of the sample (those who are 25-to 50-years-old in 1995). It 
compares the frequencies of switching in the data with the ones predicted by simulating the model.

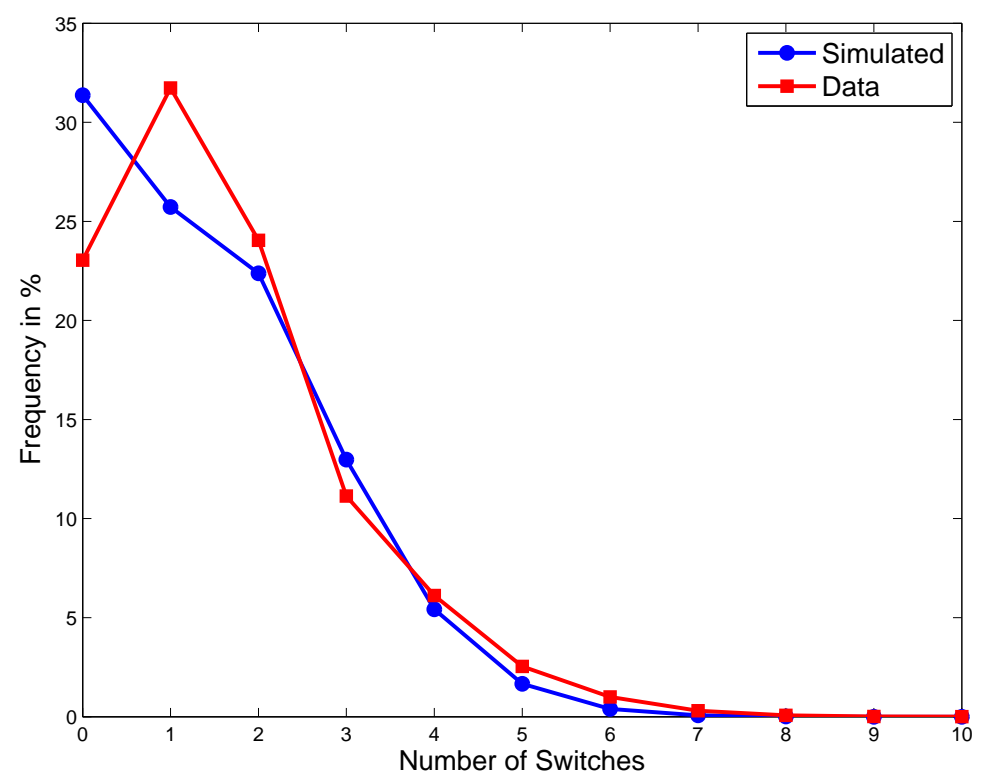

Figure C.19: Histogram for the number of times individuals switched sectors. Population: individuals always present in the sample period (25 to 50 years old in 1995). Simulated model vs. Actual Data.

Third, Figure C.20 shows histograms for the number of years individuals present in each year of the sample chose each sector. For example, in the upper-left sub-figure the model predicts that $10 \%$ of this population spent exactly 1 period in the Residual Sector whereas $7 \%$ of this population has actually spent exactly 1 year in the Residual Sector.

Overall, Figures C.18, C.19 and C.20 show that the model performs well in matching those three sets of moments, even though they were not imposed in the estimation. 

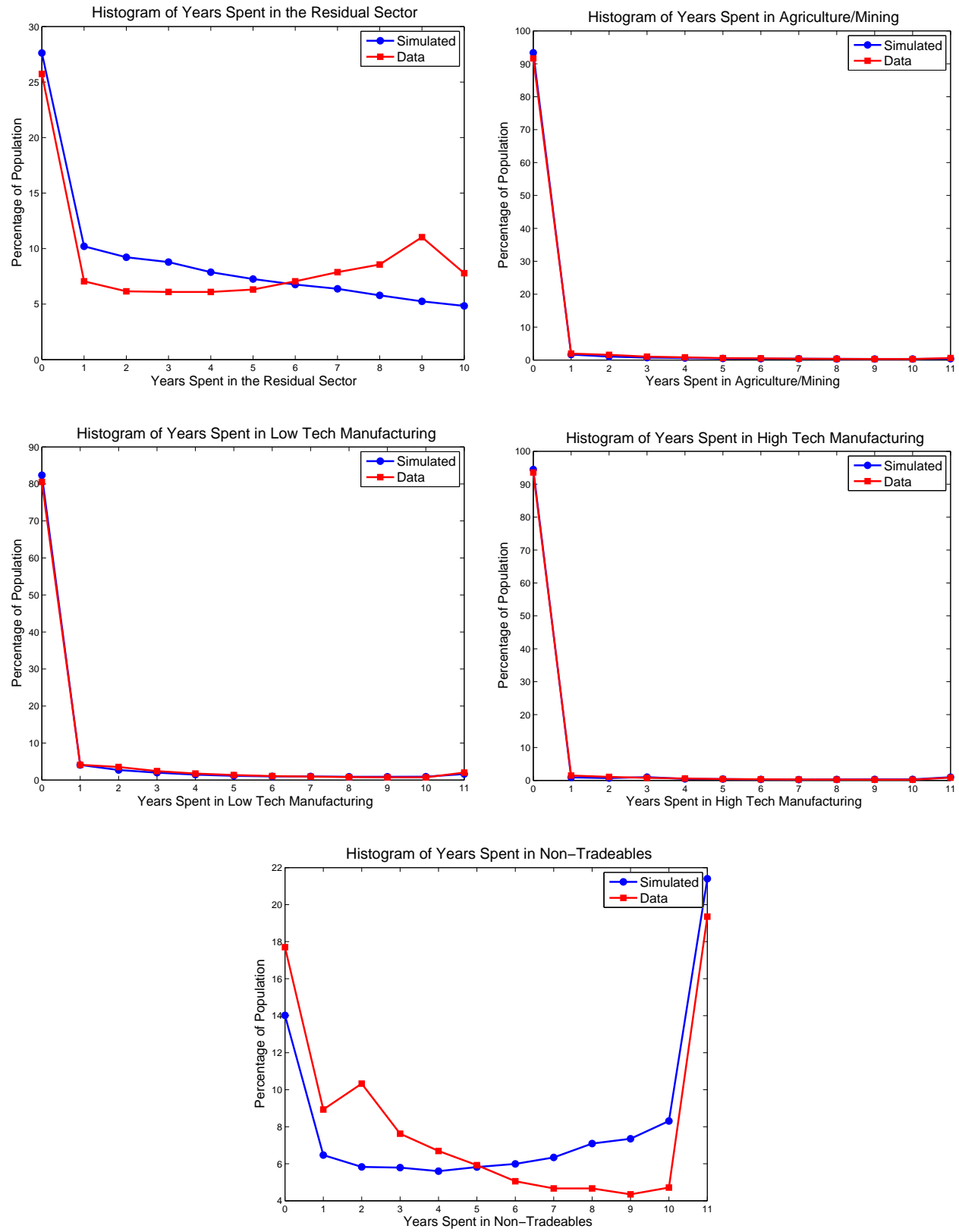

Figure C.20: Histograms for number of years spent in each sector. Population: individuals always present in the sample period (25 to 50 years old in 1995). Simulated Model vs. Actual Data

\section{Appendix - Steady State}

The economy is simulated as follows:

1. The productivity terms $z_{t}^{s} \equiv p_{t}^{s} A_{t}^{s}(s=1, \ldots, 4)$ are recovered for $t=2005$, the last period in the sample. In order to do that, we need to make an assumption on how physical capital is allocated. Since the economy-wide rental price of capital is what we can recover 
from the data, I assume efficient allocation, that is, marginal product of physical capital is equalized across sectors and equal to the rental price of physical capital in the data. It follows that:

$$
K_{2005}^{s}=\frac{\left(1-\alpha_{2005}^{0, s}-\alpha_{2005}^{1, s}\right) Y_{2005}^{s}}{r_{2005}^{K}} s=1, \ldots, 4
$$

$z_{2005}^{s}$ is is recovered as a residual of equation (1) for $s=1, \ldots, 4$ :

$$
z_{2005}^{s}=\frac{Y_{2005}^{s}}{\left(H_{2005}^{0, s}(\widehat{\Theta})\right)^{\alpha_{2005}^{0, s}}\left(H_{2005}^{1, s}(\widehat{\Theta})\right)^{\alpha_{2005}^{1, s}}\left(K_{2005}^{s}\right)^{1-\alpha_{2005}^{0, s}-\alpha_{2005}^{1, s}}}
$$

Where $\widehat{\Theta}$ is the vector of estimated parameters.

2. Initially set $A_{2005}^{s}=z_{2005}^{s}(s=1, \ldots, 4)$. Prices of all sectors (except Non-Tradeables) are set to 1 in 2005 and throughout the simulation. The price of Non-Tradeables is determined in equilibrium.

For the simulations, $A_{t}^{s}=A_{2005}^{s}(s=1, \ldots, 4)$ for all $t$, productivity will be fixed over time. Analogously, the human capital shares will be fixed at their 2005 value.

3. Entering generations all look alike. The distribution of gender and education is given by the distribution of the cohort born in 1980 (last generation to enter the estimation, in 2005). The new generations enter the simulation with zero experience.

4. As a result of the previous step, the composition of the population will change as compared to 2005, since the entering generations will look different from the entering generations used in estimation. In particular, they will be more educated the 1980 cohort is more educated than, say, the 1960 cohort). Consequently, the simulated economy will be richer in human capital than the economy used in estimation. I allow for the capital stock to accompany the growth in human capital. Hence, the economy-wide rental price of capital will be fixed to $r_{2005}^{K}$ and the capital stock will be determined so that the marginal product of capital in each sector equals $r_{2005}^{K}$. Simulate this economy until the economy reaches a steady state. After the steady state is reached, the capital stock is fixed at the steady state level.

5. The steady state price for Non-Tradeables is then normalized to 1 . The value of $A_{t}^{4}$ is reset so that $z_{t}^{4}$ satisfies (27).

6. Once the steady state is reached, the economy is shocked with a once-and-for-all tariff reduction that decreases the domestic price of High-Tech Manufacturing by $30 \%$. That is, the new domestic price of High-Tech Manufacturing is now of 0.7 and persists forever.

7. Price of Non-Tradeables and physical rental prices adjust endogenously to the shock. How the latter will adjust will depend on the assumptions made regarding the mobility of 
physical capital. 